\title{
UAM Vehicle Design with Emphasis on Electric Powertrain Architectures
}

\author{
Oliver Bertram ${ }^{1}$, Florian Jäger ${ }^{2}$, Viola Voth ${ }^{3}$, Jan Rosenberg ${ }^{4}$ \\ German Aerospace Center (DLR), Institute of Flight Systems, 38108 Braunschweig, Germany
}

The research on the system architecture of Urban Air Mobility (UAM) vehicles is a vital part within the DLR internal project HorizonUAM. One of the project goals in HorizonUAM is the development of a system concept for an air taxi. This includes research on safe and certifiable onboard systems. The aim of this article is to present results and findings with emphasis on electric powertrain architectures in the multirotor air taxi design. A preliminary design methodology was developed therefor, which enables the examination of full-electric, turbo-electric and hybrid-electric powertrains. This methodology was used in a design study to investigate the influence of different powertrain architectures on the multirotor design. Different evaluation parameters, parameter sweeps and technology exploration of batteries and fuel cell systems were applied to analyze and evaluate their impact on the UAM vehicle design. The main design drivers are the mass of the energy sources and the overall powertrain efficiency, which have a direct impact on the evaluation parameters like power and energy efficiency, maximum take-off mass, and payload fraction. The study showed that different powertrain architectures could lead to opposite vehicle design criteria. Therefore, a clear solution for an advantageous powertrain architecture could not be found. Hybrid-electric solutions, e.g. fuel cell and battery systems or parallel hybrid-electric systems, offer the possibility of increasing efficiency in different flight phases through suitable power management while increasing system complexity. The disadvantage of a high battery mass of a full-electric solution could thus be at least partially reduced.

\section{Nomenclature}

A. Abbreviations

$\begin{array}{ll}\text { AMC } & =\text { accepted means of compliance } \\ \text { AoA } & =\text { angle of attack } \\ \text { B } & =\text { battery } \\ \text { CSFL } & =\text { continued safe flight and landing } \\ \text { DLR } & =\text { German aerospace center } \\ \text { EASA } & =\text { European aviation safety agency } \\ \text { EM } & =\text { electrical machine/generator } \\ \text { eVTOL } & =\text { electric VTOL aircraft } \\ \text { F } & =\text { fuel } \\ \text { FC } & =\text { fuel cell } \\ \text { GB } & =\text { gearbox } \\ \text { GT } & =\text { gas turbine } \\ \text { H } & =\text { hydrogen }\end{array}$

$\begin{array}{ll}\text { IGE } & =\text { in ground effects } \\ \text { ISA } & =\text { international standard atmosphere } \\ \text { M } & =\text { Mach } \\ \text { MSL } & =\text { mean sea level } \\ \text { MTOM } & =\text { maximum take-off mass } \\ \text { PAX } & =\text { number of passengers } \\ \text { PM } & =\text { power management } \\ \text { R } & =\text { rotor } \\ \text { SPPH } & =\text { serial/parallel partial hybrid } \\ \text { SoC } & =\text { state of charge } \\ \text { TLARs } & =\text { top-level aircraft requirements } \\ \text { UAM } & =\text { urban air mobility } \\ \text { VTOL } & =\text { vertical take-off and landing }\end{array}$

\footnotetext{
1 Research Group Leader and Deputy Head of Department, Department Safety-Critical Systems \& Systems Engineering, oliver.bertram@dlr.de

${ }^{2}$ Research Scientist, Department Safety-Critical Systems \& Systems Engineering

${ }^{3}$ Research Scientist, Department Safety-Critical Systems \& Systems Engineering

${ }^{4}$ Research Student, Department Safety-Critical Systems \& Systems Engineering
} 


\section{B. Symbols}

\begin{tabular}{|c|c|c|}
\hline$\alpha$ & $=$ & angle of attack, rad \\
\hline$\eta$ & $=$ & powertrain efficiency \\
\hline$\eta_{\text {bat }}$ & $=$ & battery efficiency \\
\hline$\eta_{\text {comp }}$ & $=$ & component efficiency \\
\hline$\kappa$ & $=$ & induced power coefficient \\
\hline$\mu$ & $=$ & advance or tip speed ratio \\
\hline$\rho$ & $=$ & air density, $\mathrm{kg} / \mathrm{m}^{3}$ \\
\hline$\sigma$ & $=$ & rotor solidity \\
\hline$\varphi$ & $=$ & shaft power ratio \\
\hline$\Phi$ & $=$ & supplied power ratio \\
\hline$\Omega$ & $=$ & rotor speed, rad/s \\
\hline A & $=$ & rotor disk area, $\mathrm{m}^{2}$ \\
\hline $\mathrm{C}_{\mathrm{D} 0}$ & $=$ & mean airfoil drag coefficient \\
\hline $\mathrm{D}_{\text {cruise }}$ & $=$ & distance in cruise segment, $\mathrm{m}$ \\
\hline $\mathrm{D}_{\text {cruise,climb }}$ & $=$ & distance in cruise climb segment, $\mathrm{m}$ \\
\hline $\mathrm{D}_{\text {cruise,desc. }}$ & $=$ & distance in cruise descent segment, $\mathrm{m}$ \\
\hline $\mathrm{D}_{\text {req. }}$ & $=$ & required total mission range, $\mathrm{m}$ \\
\hline $\mathrm{E}_{\mathrm{bat}}$ & $=$ & energy of the battery, Wh \\
\hline $\mathrm{E}_{\text {fuel }}$ & $=$ & energy of fuel, Wh \\
\hline E & $=$ & energy of hydrogen, Wh \\
\hline f & $=$ & equivalent flat plate area, $\mathrm{m}^{2}$ \\
\hline $\mathrm{m}_{\text {bat }}$ & $=$ & battery mass, kg \\
\hline $\mathrm{m}_{\mathrm{comp}}$ & $=$ & mass of powertrain components, $\mathrm{kg}$ \\
\hline $\mathrm{m}_{\text {fuel }}$ & $=$ & fuel mass, $\mathrm{kg}$ \\
\hline $\mathrm{m}_{\text {Group }}$ & $=$ & mass of aircraft components group, $\mathrm{kg}$ \\
\hline $\mathrm{m}_{\text {hydrogen }}$ & $=$ & hydrogen mass, kg \\
\hline $\mathrm{m}_{\text {other,sys }}$ & $=$ & mass of other systems, kg \\
\hline mMTOM & $=$ & maximum take-off mass, $\mathrm{kg}$ \\
\hline $\mathrm{N}$ & $=$ & number of rotors \\
\hline $\mathrm{P}_{0}$ & $=$ & profile power, W \\
\hline $\mathrm{P}_{\text {bat,max }}$ & $=$ & maximum battery power, $\mathrm{W}$ \\
\hline$P_{\text {climb }}$ & $=$ & climb power, W \\
\hline $\mathrm{R}$ & $=$ & rotor radius, m \\
\hline
\end{tabular}

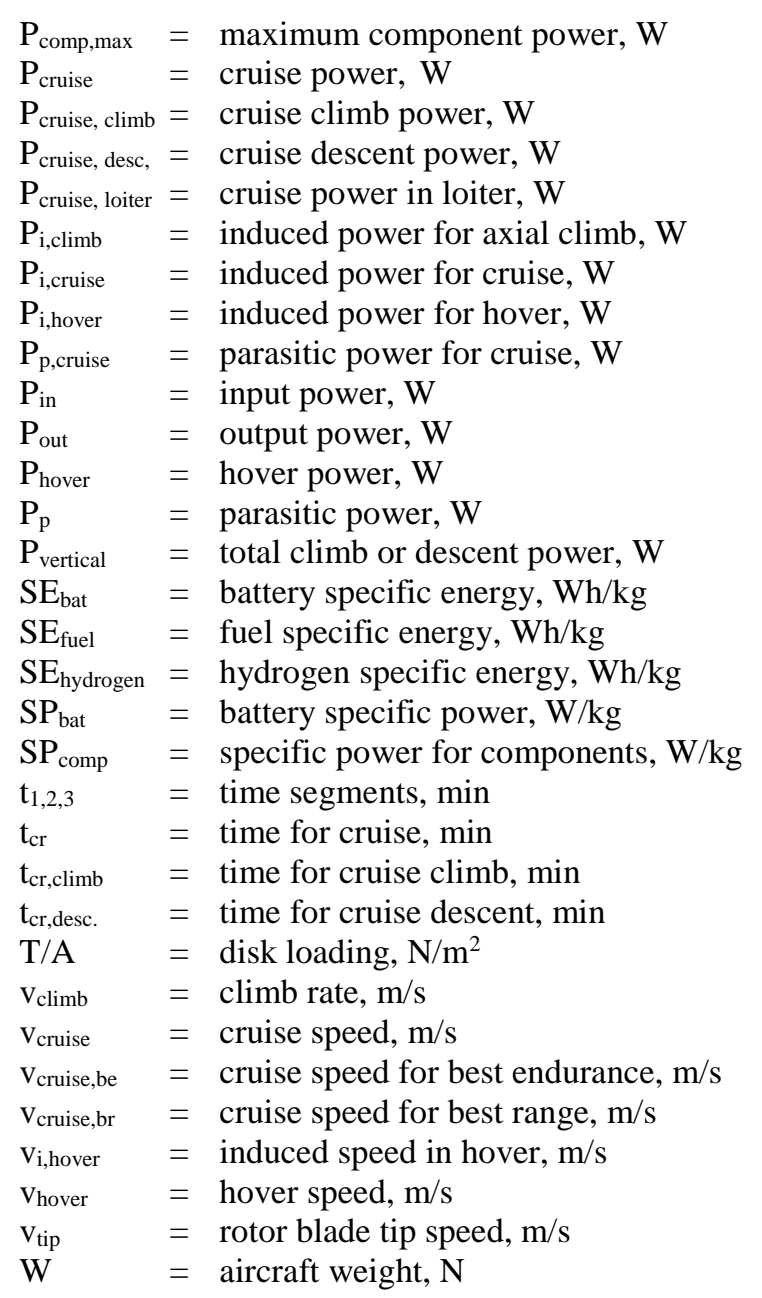

\section{Introduction}

Due to the steadily growing population in urban agglomerations and the concomitant overloading of existing transport infrastructure, the development of airspace over urban areas is increasing as part of the Urban Air Mobility (UAM) concept. Efficiency, safety, practicability, sustainability and affordability are just a few features that describe the vision of future urban mobility.

The HorizonUAM project [1] at the German Aerospace Center (DLR) deals with some of the aspects of this vision. It combines research about UAM vehicles, the corresponding infrastructure, the operation of UAM services, as well as public acceptance and market development of future urban air transportation. Possible UAM market scenarios up to the year 2050 are analyzed and economic aspects assessed. In HorizonUAM competencies and current research topics including propulsion technologies, flight system technologies, communication and navigation go along in conjunction with the findings of modern flight guidance techniques and airport technologies. Furthermore, the system design for future air taxis is carried out on the basis of vehicle family concepts, onboard systems, aspects of safety and cyber security as well as the certification of autonomy functions. Selected concepts for flight guidance, communication and navigation technology will also be demonstrated with drones in a scaled urban scenario.

In UAM concepts, autonomous flying taxis are important elements. A large number of different prototypical air taxi concepts already exist today, which differ from conventional aircraft, among others, particularly in terms of their vertical take-off and landing (VTOL) capabilities. The distinction from conventional rotary wing aircraft, on the other hand, is based on the use of distributed, electric drives, in particular if more than two lift and/or thrust units are used to generate lift during vertical take-off or landing. 
One of the project goals in HorizonUAM is the development of a system concept for an air taxi. For this purpose, the Safety-Critical Systems and Systems Engineering department at the DLR Institute of Flight Systems conducts research in the field of safe and certifiable onboard systems.

The aim of this article is to present and discuss the results and findings in the conceptual onboard systems design of UAM vehicles. In this contribution, a special focus is set on the electric powertrain architectures. The following research questions will be addressed:

- What is the impact of different electric powertrain architectures on the design of electric VTOL aircraft (eVTOL)? Which powertrain architecture should best be chosen for which mission?

- What is the impact of the degree of hybridization on different powertrain architectures and on the feasibility of an eVTOL concept?

- What is the influence of future battery technology on the eVTOL characteristics?

- What influence does an electric fuel cell architecture have on the entire eVTOL design compared to a fullelectric architecture based on batteries?

For this purpose, chapter III describes the challenges in the design of the onboard systems, especially of electric powertrains, identified by literature research. Chapter IV describes a developed preliminary design method that enables full-electric, turbo-electric and hybrid-electric powertrain systems to be investigated. In chapter $\mathrm{V}$ this methodology is applied in the context of a design study that has been carried out. The study results with emphasis on electric powertrains are presented and discussed. These findings are to flow into the overarching system concept of the air taxi. Chapter VI gives a conclusion and an outlook on the further planned activities in the context of the HorizonUAM project.

\section{Onboard System Design Challenges}

At the beginning, a literature research on the current state of the art of onboard systems was carried out [2]. The aim of the research was to identify relevant technologies, subsystems and commercially available equipment as well as suitable conceptual design methods.

A large number of different UAM vehicle concepts already exist today [3]. Most of the concepts are prototypical developments that still require a lot of research. Only a few concepts are on the way to approval, such as the VoloCity [4]. Based on studies carried out by NASA [5], various research areas for UAM vehicles were identified. These areas are shown in Fig. 1. Further research fields include autonomy, certification, communication and navigation as well as technology integration.

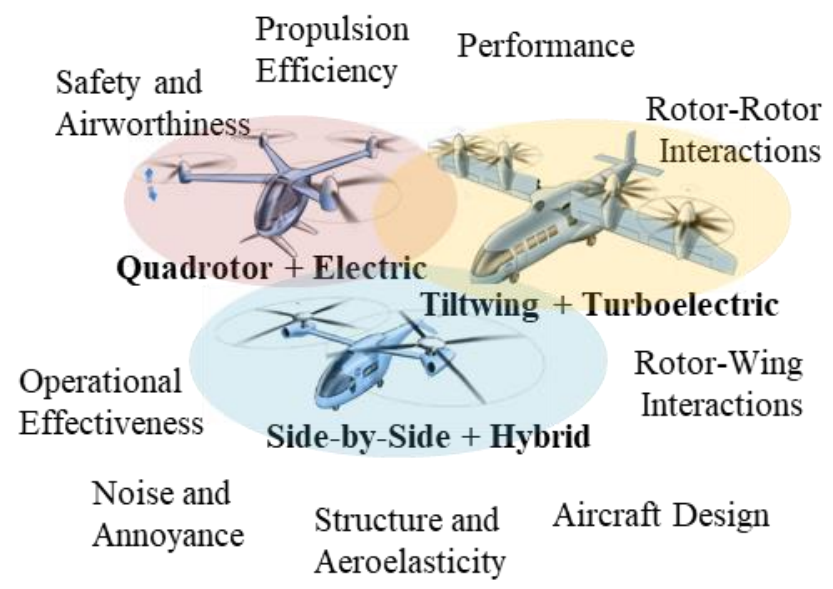

Fig. 1 Research fields for UAM vehicle concepts [5]

Basically, the design of an aircraft is highly complex and multidisciplinary, with a wide variety of interactions and influences between the different design disciplines. The description of the various interactions would exceed the scope of this article. Therefore, only the aspects related to the electric powertrain system are considered in more detail below. The overall goal of this paper is to assess the suitability and potential drive trains in UAM vehicles. 


\section{A. Power Requirements}

A distinction can be made between air taxis, for instance, in cruise configuration with rotating wings (e.g. multirotor, conventional and coaxial helicopters) and cruise configuration with fixed wings (e.g. lift and cruise, tilt duct, tilt wing). From a flight performance-based perspective, these different configurations are typically characterized by their hovering and cruising efficiency. Values of these design characteristics can be found in the literature and can provide an initial estimate for the design space of potential aircraft architectures [6].
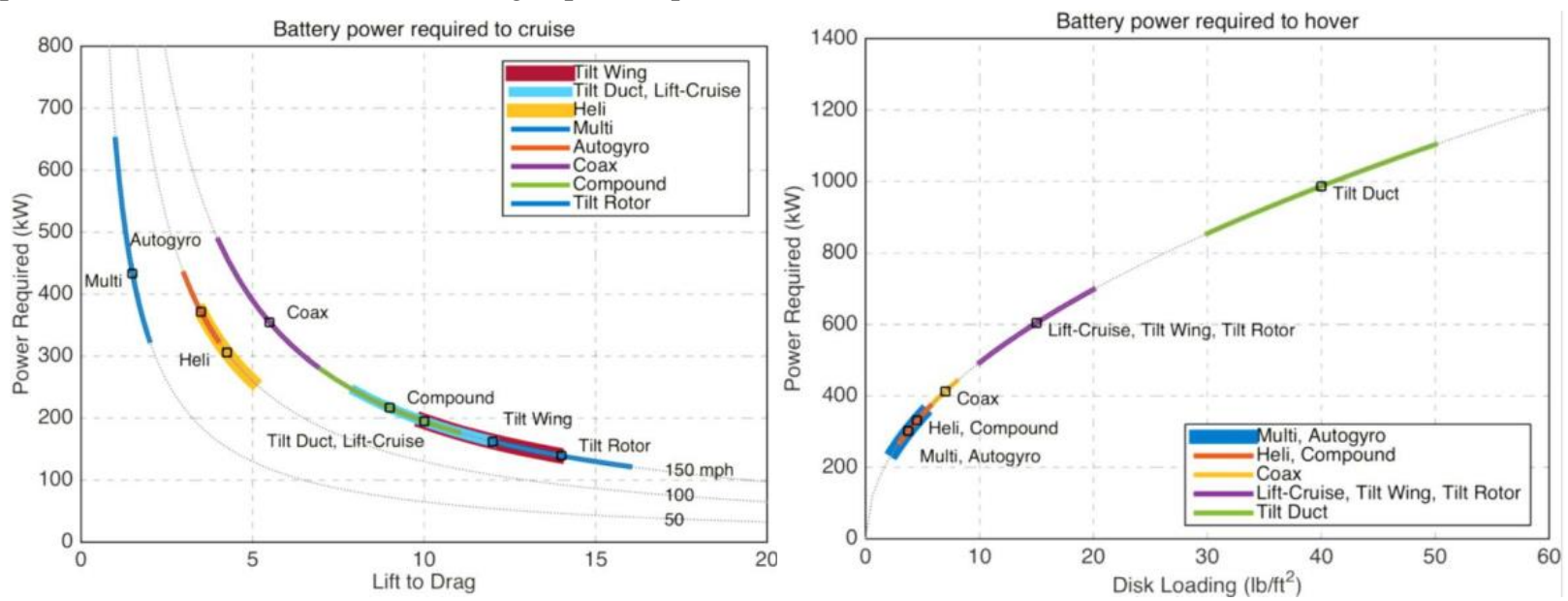

Fig. 2 Battery-electric power requirements in cruise (left) and in hover (right) for different vehicle configurations [6]

Due to the difference in flight performance, different aircraft configurations also have different battery power requirements. This fact is shown in Fig. 2 for an exemplary vehicle with a maximum take-off mass (MTOM) of $2268 \mathrm{~kg}$ at ISA MSL (mean sea level) for cruise flight and hover. For other flight phases, environmental conditions and mission requirements such as cruise speed, payload, reserves, etc., these power requirements differ and thus, the battery size and dimensions change with a strong impact on the overall size and weight of the aircraft. Fig. 2 also shows that the battery power requirements strongly depend on the aircraft configuration and its related lift-to-drag ratio and disk loading characteristics.

\section{B. System Technology Aspects}

Today, electric powertrain and battery technologies are the enablers for the implementation of eVTOL. Electric powertrains are simpler than gas turbines and mechanical drive trains and have lower maintenance costs, which leads to lower vehicle costs. Electric drives are emission-free, low-noise and "green" if sustainable energy is used. Decentralized, distributed electrical drive concepts play a major role for safety and reliability.

The battery technology available today, however, leads to a relatively high component weight with reduced payload ratio and enables only short flight times or ranges in eVTOL applications compared to an aircraft with a conventional propulsion system. This has a major impact on the vehicle design as well as on operational aspects of the individual eVTOL or the entire eVTOL fleet. Nevertheless, due to the high demand and the increased production in the automotive industry, battery costs are falling continuously, which could then lead to lower eVTOL cost. [7]

However, with improving battery technology, leading to, for instance, increasing specific power or energy density, the payload ratio and the ranges increase accordingly. In order to meet these challenges in today's battery technology, alternatively turbo-electric or hybrid-electric powertrain concepts can be used as bridge technology. Exemplary system architectures can be found, for instance, in [8] and [9].

In addition, fuel cell systems can also be used as an electrical energy source. However, these systems bring new requirements, e.g. on the cooling or tank system. However, the use of fuel cell systems enables a continuous electrical energy output for higher endurance of the vehicle, a pollutant-free, environmentally friendly reaction process and a noiseless functionality [10]. Short-term peak performances (e.g. during take-off or landing) can be provided in conjunction with a battery system. So far, no approved air taxi that is powered by a fuel cell system has been developed to the best of the authors' knowledge. Challenges and research needs lie in the crash safety of the hydrogen-carrying components, the storage of liquid or gaseous hydrogen, the limited service life and the higher system weight. 
In the field of electric powertrain architectures, research is taking place to increase the specific power and overall efficiency in order to reduce the weight of the drive system and the amount of heat to be dissipated, and to decrease the required power level.

\section{Safety-Critical Design Aspects}

Electric propulsion systems face aircraft designers and safety engineers with new and unknown challenges. The new danger in eVTOL are lithium batteries. The main risk here is the thermal runaway, where rapid, self-sustaining temperature and pressure increases in battery cells lead to an external fire. Reasons for thermal runaway can be, for example, deep discharge, overcharging and internal short circuits. Toxic gases can also be released and crash safety must be guaranteed [8].

In addition, electrical high-voltage systems represent another new type of danger in flight when energy is released through short circuits and arcs. This at least leads to a deterioration in the performance of the powertrain system and could also lead to a fire. At the same time, however, high-voltage systems also pose a risk for maintenance and ground handling personnel [8].

However, the electric powertrain systems also offer new potential for increasing safety. For example, aircraft with distributed, electric propulsion can be more tolerant of bird strikes and engine losses than propulsion configurations with fewer engines. In the design, the individual components can be designed redundantly and networked with one another in such a way that the failure of individual components does not lead to a safety-critical situation. There are also more options of redistributing the power to other drives in the event of a component failure than with mechanical drive trains. This enables simpler, less complicated and more effective system architectures [8].

In summary, electric powertrain systems have the potential to improve system safety in the event of failure conditions and to eliminate hazards associated with jet fuel. At the same time, however, new risks are being introduced, such as the thermal runaway of battery packs. Methods to demonstrate the safety of electrical systems, demonstrator service experience, and best design practices will be crucial with respect to reducing risk in this area [8].

\section{Certification Aspects}

In order to operate in European airspace, eVTOL also require a type certification by EASA. Due to the increasing number of inquiries on this topic and the lack of suitable certification regulations, EASA has published a complete set of technical specifications in the form of a "Special Condition for Vertical Take-Off and Landing Aircraft" (SCVTOL) [11]. Since the VTOL aircraft currently under development share properties both with conventional aircraft and helicopters, there are also serious differences such as the distributed drive units. Individual aspects from the certification regulations CS-23 [12] for smaller aircraft and CS-27 [13] for small helicopters are included in the special conditions and supplemented by new regulations specially adapted to the unique characteristics of VTOL aircraft.

In addition, the first edition of the "Proposed Means of Compliance with the Special Condition VTOL" was released for public consultation and comment [14]. Therein, a first set of Accepted Means of Compliance (AMCs) can be found. This enables individual paragraphs of the special condition to be verified. However, the document will only become binding after the public consultation phase and the transition to Accepted Means of Compliance. By using a special condition, EASA was able to react quickly to the growing number of certification questions relating to VTOLcapable aircraft and to not have to initiate the much longer process of creating a certification specification. However, this still needs to be done later and on the basis of the knowledge gained through the application of the SC-VTOL. Until the publication of a final "CS-VTOL", the special condition serves as an interim solution.

The SC-VTOL defines the technical specifications for the person-carrying VTOL aircraft of the "small" category that are heavier than air. These specifications are not restricted to specific systems and components:

- Maximum capacity of 9 or fewer passengers

- Maximum certified take-off mass of 3,175 kg or less

- Aircraft must have at least two lift/drive units that are used to generate lift during the vertical take-off or landing phase and to control the aircraft.

- Restriction only for aircraft that are not pressurized and whose maximum calibrated airspeed in normal operation does not exceed 250 knots or Mach 0.6

Certification takes place either in the "basic" or "enhanced" category. A grouping in the category "enhanced" has to take place if an operation over metropolitan areas is planned or if the aircraft is to be used for the commercial transport of people, which is usually the case with air taxis. For these aircraft, it must be proven that they are still able to make a safe onward flight and a safe landing (CSFL, "Continued Safe Flight and Landing") on one of the provided vertiport without the requirement of extraordinary pilot skills. This has to be done for the case of a single failure not classified as catastrophic or a catastrophic combination of failures. With regard to the configurations in the project, these requirements are more than sufficient. 
A description and analysis of the individual requirements of the SC-VTOL e.g. on the electric powertrain system is not further carried out here. In general, however, every system or its components must be installed in accordance with its applicable limitations. When developing the systems, it should be noted that

- every catastrophic failure is "extremely improbable" and cannot occur as a result of a single failure,

- every hazardous failure case is "extremely remote" and

- $\quad$ every serious failure is "remote".

Systems whose failure condition could lead to a catastrophic or hazardous event must be able to be monitored by means of suitable monitoring during operation. The operation of other systems that do not have to meet these requirements must also not pose a risk to the aircraft or the occupants in the entire operating area. According to the proposed AMCs, all failures that prevent the aircraft from safely continuing its flight and landing are to be classified as catastrophic in the context of the safety analysis. The failure rates to be verified and the "Function Development Assurance Level" (FDAL) to be used for the individual failure categories can be found in Table 1

Table 1 Failure rates and FDAL of the individual failure categories [11]

\begin{tabular}{|c|c|c|c|c|c|}
\hline \multirow{2}{*}{ Category } & \multirow{2}{*}{ Max. PAX } & \multicolumn{4}{|c|}{ Classification } \\
\cline { 3 - 6 } & & MIN & MAJ & HAZ & CAT \\
\hline \multirow{2}{*}{ Enhanced } & - & $\leq 10^{-3}$ & $\leq 10^{-5}$ & $\leq 10^{-7}$ & $\leq 10^{-9}$ \\
\cline { 3 - 6 } & & FDAL D & FDAL C & FDAL B & FDAL A \\
\hline \multirow{4}{*}{ Basic } & \multirow{2}{*}{$7-9$ PAX } & $\leq 10^{-3}$ & $\leq 10^{-5}$ & $\leq 10^{-7}$ & $\leq 10^{-9}$ \\
\cline { 3 - 6 } & \multirow{2}{*}{$2-6$ PAX } & $\leq 10^{-3}$ & $\leq 10^{-5}$ & $\leq 10^{-7}$ & $\leq 10^{-8}$ \\
\cline { 3 - 6 } & \multirow{2}{*}{$0-1$ PAX } & $\leq 10^{-3}$ & $\leq 10^{-5}$ & $\leq 10^{-6}$ & $\leq 10^{-7}$ \\
\cline { 3 - 6 } & & FDAL D & FDAL C & FDAL C & FDAL B \\
\cline { 3 - 6 } & & FDAL D & FDAL C & FDAL C & FDAL C \\
\hline \multicolumn{7}{|c|}{ MIN: Minor; MAJ: Major: HAZ: Hazardous; CAT: Catastrophic } \\
\hline
\end{tabular}

\section{Model-based Design Methodology}

In the last chapter, the challenges in the design of electrical powertrain as part of the onboard systems were presented. The entire onboard system consists of various subsystems such as flight controls, avionics, etc. with a large number of components. A large number of system-related questions arise from the literature research, particularly for electrical powertrains. These range from a suitable definition of the system architecture and the technology level, the safety-critical design, parameter, sensitivity and feasibility studies to the validation and verification of the requirements.

A model-based design methodology is presented in this chapter. This methodology should make it possible to carry out conceptual studies and to examine the influence of different electric powertrain architectures on the eVTOL design in an early design phase. Safety and reliability play a very important role for design and approval (see sections $\mathrm{C}$ and $\mathrm{D}$ ) but have not yet been considered in the methodology. Rather, the purpose is to preselect feasible concepts and transfer them to a subsequent, more detailed design step with safety and reliability analyzes.

\section{A. Methodology Definition}

A model-based approach was chosen as part of the project. This approach should make it possible to answer relevant questions, to allow investigations of influences and interactions in the design of the eVTOL and the overall system of systems and to contribute to the design of the air taxi system concept.

A conceptual design method was developed for the model-based approach, which is shown in Fig. 3. The methodology consists of the three main steps

- definition of inputs,

- $\quad$ sizing loop and

- analysis of outputs.

These steps are explained in more detail in the following sections. 


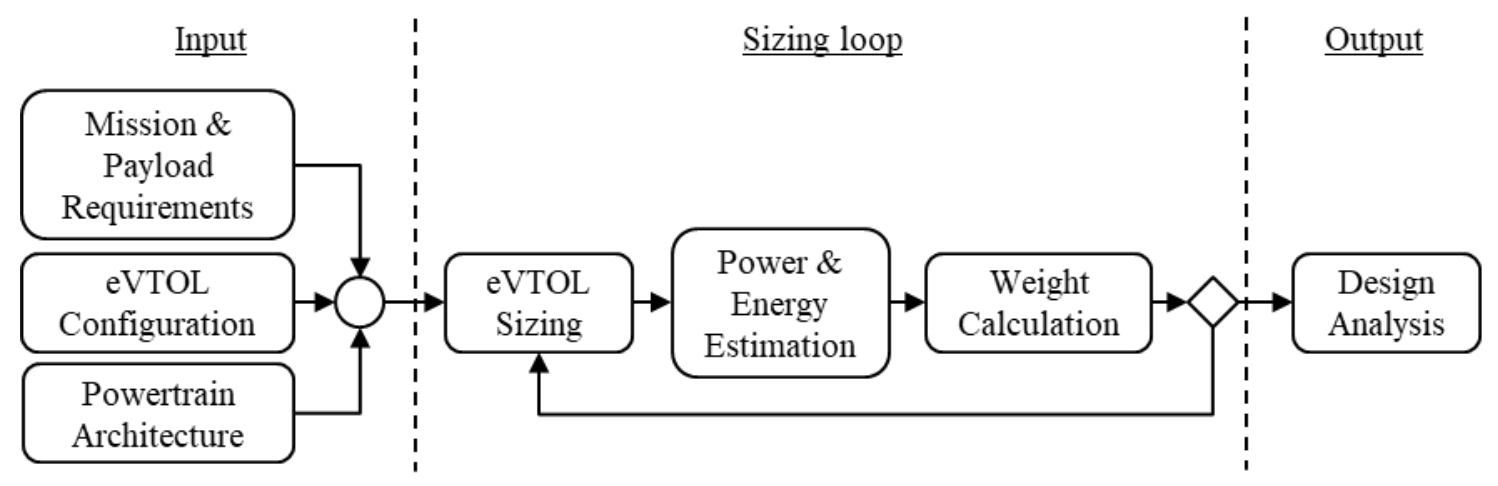

Fig. 3 Conceptual design methodology

\section{Input Definition}

Three input categories are required for the methodology. The first category includes the mission and payload requirements. During the HorizonUAM project, for example, various use cases such as intra-city, airport shuttles, etc. with associated top-level aircraft requirements (TLARs) were defined and technology assumptions were made for the years 2025 and 2050. The profile for the design reference mission of the intra-city use case is shown in Fig. 4 along with the specific TLARs for this study (see section V.A.1).

Second, the eVTOL configuration must be defined with size-relevant parameters such as the initial, maximum take-off mass, disk loading and number of rotors. Other input parameters are listed in Table 2. In principle, there are no restrictions with respect to the choice of configurations and parameters. In HorizonUAM it was decided beforehand to investigate a multirotor configuration for the air taxi system concept. Therefore, the focus is on this configuration.

The third category defines the powertrain architecture. In addition to full-electric systems (battery or fuel cell), turbo-electric or hybrid-electric system architectures can also be used as bridging technology. Each individual powertrain architecture consists of a set of components such as electric motors, generators, power electronics, gas turbines, gears, rotors, etc., which are connected to one another. The definition of the architecture should make it possible to answer different design and research questions. The inputs described are finally put into the sizing loop, which is described in the next section.

\section{Sizing Loop}

The sizing loop shown in Fig. 3 comprises the eVTOL sizing, the power and energy estimation and the weight calculation of the structural and system components.

Based on the input data, an initial eVTOL sizing is carried out with regard to the mission requirements and an initial MTOM. For this purpose, a performance model of the multirotor was developed based on momentum theory, respectively actuator disk theory. This model is described in more detail in section IV.B.1 and is used to calculate the flight performance in each individual flight phase of the mission.

The performance and energy estimations for the systems are carried out using this model. For this purpose, a nonlinear equation system is set up and solved for each defined powertrain architecture. The powertrain model is described in section B.2. As a result, the power requirement for each individual powertrain component as well as the overall energy requirement of the mission is determined.

On the basis of the performance and energy parameters, the weights of the components and energy sources (battery, kerosene, hydrogen) of the powertrain system are then determined. In addition, the weights of structural components and other systems such as flight controls, environmental control system and avionics are estimated using simplified models and assumptions (see section IV.B.3 and IV.B.4). The calculated weights of all components are used to determine a new total weight for the eVTOL.

Finally, the convergence is checked. As long as the convergence criterion is not met, the MTOM is updated with these component weights and the next iteration begins. Also, other configuration parameters like rotor disk area and rotor radius are updated with each iteration. If the criterion is met, the results of each converged solution are provided as output for the subsequent design analysis.

\section{Analysis of Outputs}

In the last step, the results of the sizing loop are analyzed with regard to the design and research questions. The output includes the component and group weights as well as the weight proportions for the eVTOL with different powertrain architectures. In addition, powertrain efficiency is addressed and analyzed (see section V.B). 


\section{B. Sizing and Performance Models}

The following section describes the different sizing and performance models that are used in the sizing loop.

\section{Flight Performance Model}

To calculate the flight performance of the multirotor, a performance model based on the momentum theory was developed using the works of Leishman [16]. The rotor is abstracted as an actuator disk, whereby the number and design of the rotor blades, the rotor hub, the fuselage etc. are not considered. All the rotors have been considered as isolated rotors. The momentum theory represents a significant reduction of the highly complex aerodynamic processes at the rotor. The flow itself is assumed to be one-dimensional, quasi-stationary, incompressible and frictionless. In Ground Effects (IGE) and the Angle of Attack (AoA) were also neglected. Finally, the basic equations for the conservation of mass, momentum and energy were used to determine the essential relationships as a basis for determining the required performance. Based on these relationships, the required flight performance in the various flight phases was determined.

\section{Hover Performance}

An important characteristic is the hover performance $\mathrm{P}_{\text {hover }}$, which is made up of the profile performance $\mathrm{P}_{0}$, i.e. the zero drag of the rotor blade profiles, and the real, induced performance $\mathrm{P}_{\mathrm{i}, \mathrm{hover}}$ :

$$
\mathrm{P}_{\text {hover }}=\mathrm{P}_{0}+\mathrm{P}_{\mathrm{i} \text { hover }}
$$

The induced hover performance can be estimated with the air density $\rho$ and the induced power coefficient $\kappa$, which are assumed as constant. The rotor disk area $\mathrm{A}$ and the aircraft weight $\mathrm{W}$ are variable parameters related to the current iteration of the multirotor configuration:

$$
\mathrm{P}_{\mathrm{i}, \text { hover }}=\kappa \cdot \mathrm{W} \cdot \underbrace{\sqrt{\frac{\mathrm{W}}{2 \cdot \rho \cdot \mathrm{A}}}}_{\mathrm{v}_{\mathrm{i}, \text { hover }}}
$$

The profile power can be estimated with the blade tip speed $\mathrm{v}_{\text {tip }}$, the solidity $\sigma$, the mean airfoil drag coefficient $\mathrm{C}_{\mathrm{D} 0}$ and the tip speed ratio $\mu$. In case of hover, the cruise speed $v_{\text {cruise }}$ is zero and thus the tip speed ratio $\mu$ is omitted.

$$
\begin{gathered}
\mathrm{P}_{0}=\rho \cdot \mathrm{A} \cdot \mathrm{v}_{\text {tip }}^{3} \cdot \frac{\sigma}{8} \cdot \mathrm{C}_{\mathrm{D} 0} \cdot\left(1+4.5 \cdot \mu^{2}\right) \\
\mu=\frac{\mathrm{v}_{\text {cruise }} \cdot \cos \alpha}{\Omega \cdot \mathrm{R}} \approx \frac{\mathrm{v}_{\text {cruise }}}{\mathrm{v}_{\text {tip }}}
\end{gathered}
$$

Performance in Vertical Climb and Vertical Descent

The total power in vertical climb (or respectively descent) can be estimated with the profile power $\mathrm{P}_{0}$, the climb power $\mathrm{P}_{\text {climb }}$ and the induced power for axial climb $\mathrm{P}_{\mathrm{i}, \mathrm{climb}}$ :

$$
\mathrm{P}_{\text {climb }, \text { total }}=\mathrm{P}_{0}+\mathrm{P}_{\mathrm{i}, \text { climb }}+\mathrm{P}_{\text {climb }}
$$

The climb power is calculated with the aircraft weight $\mathrm{W}$

$$
\mathrm{P}_{\text {climb }}=\mathrm{W} \cdot \mathrm{v}_{\mathrm{climb}}
$$

According to [16] and [17], the induced power for axial climb $\mathrm{P}_{\mathrm{i}, \mathrm{climb}}$ can be computed in relation to the induced hover power. This equation can be used for small climb or very small descent rates, which is the case in this paper. For higher vertical speeds, especially in descent, this formulation may lose validity:

$$
\mathrm{P}_{\mathrm{i}, \text { climb }}=\mathrm{P}_{\mathrm{i}, \text { hover }} \cdot\left[\frac{\mathrm{v}_{\text {climb }}}{2 \cdot \mathrm{v}_{\mathrm{i}, \text { hover }}}+\sqrt{\left(\frac{\mathrm{v}_{\text {climb }}}{2 \cdot \mathrm{v}_{\mathrm{i}, \text { hover }}}\right)^{2}+1}\right]
$$




\section{Cruise Performance}

Normally, the AoA of the blade tip path plane tilts the thrust vector forward and allows the multirotor to accelerate and cruise. Assuming that this angle is neglected $\left(\alpha=0^{\circ}\right)$ and thrust equals weight $(T=W)$, rough analytical solutions for the required cruise performance can be used. According to [17], the cruise performance can be determined using

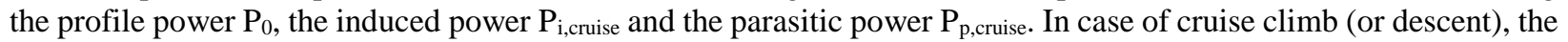
climb power is additionally required:

$$
\mathrm{P}_{\text {cruise }}=\mathrm{P}_{0}+\mathrm{P}_{\mathrm{i} \text {,cruise }}+\mathrm{P}_{\mathrm{p}, \text { cruise }}+\mathrm{P}_{\text {climb }}
$$

The power induced during cruise can be determined via the cruise speed $v_{\text {cruise }}$, the induced speed in hover $v_{i, \text { hover }}$ as well as the weight $\mathrm{W}$ and the induced power coefficient $\kappa$ :

$$
P_{i, \text { cruise }}=\kappa \cdot W \cdot \sqrt{-\frac{v_{\text {cruise }}^{2}}{2}+\sqrt{\frac{v_{\text {cruise }}^{4}}{4}+v_{i, \text { hover }}^{4}}}
$$

Power losses resulting from friction and flow separations on the airframe, the rotor hub, landing gear, antennas

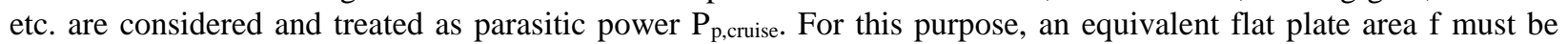
assumed or otherwise determined [17]:

$$
\mathrm{P}_{\mathrm{p}, \text { cruise }}=0.5 \cdot \rho \cdot f \cdot \mathrm{v}_{\text {cruise }}^{3}
$$

\section{Cruise Speeds for Best Endurance and Best Range}

In addition to the performance parameters listed above, the cruise speeds for best range $v_{\text {cruise,br }}$ and best endurance $\mathrm{v}_{\text {cruise,be }}$ can be determined analytically according to [16]:

$$
\begin{aligned}
\mathrm{v}_{\text {cruise }, \mathrm{br}} & =\sqrt{\frac{\mathrm{W}}{2 \cdot \rho \cdot \mathrm{A}}} \cdot\left(\frac{4 \cdot \kappa}{\mathrm{f} / \mathrm{A}}\right)^{0.25} \\
\mathrm{v}_{\text {cruise }, \mathrm{be}} & =\sqrt{\frac{\mathrm{W}}{2 \cdot \rho \cdot \mathrm{A}}} \cdot\left(\frac{4 \cdot \kappa}{3 \cdot \mathrm{f} / \mathrm{A}}\right)^{0.25}
\end{aligned}
$$

For this, the rotor disk area $\mathrm{A}$, the equivalent flat plate area $\mathrm{f}$, the induced velocity in hover and the empirically determined induced power coefficient $\kappa$ are required. In the context of this work, the value of $\kappa$ is assumed to be 1.15. The determined cruise speeds are used in different flight phases. An assignment can be found in the definition of the mission segments for the study carried out (see Table 3).

\section{Powertrain Model}

In the following, an analytical, stationary model for the design of electrical powertrain architectures is presented for the estimation of the power and energy quantities. This model is based on the work of de Vries [9] and is used to calculate the power of each individual powertrain element for a given flight performance requirement. This performance requirement is calculated using the eVTOL performance model.

Based on the specified performance requirements, the model should also offer the option of calculating various powertrain architectures. De Vries suggested different (hybrid) electrical architectures for his model [9]. His investigations showed that the Serial/Parallel Partial Hybrid (SPPH) architecture can be used as a general model to configure and calculate other hybrid and fully electric architectures using two power control parameters, namely the supplied power ratio $\Phi$ and the shaft power ratio $\varphi$. With the help of these power control parameters, a subsequent analysis and optimization of the power settings during the mission can also be made possible [9]. However, this is not part of this work.

For this work, the supplied power ratio $\Phi$ is relevant. This ratio represents the amount of energy taken from the electrical energy source (e.g. batteries) in relation to the total amount of energy that is taken from all energy sources (e.g. kerosene, batteries, hydrogen) for a specific point of the mission. As part of the study carried out (see chapter V), 
the proportion of the electrical power consumed is varied for the hybrid-electric powertrain architectures $(\Phi=[0.2$, $0.5,0.8])$.

The powertrain model consists of a total of ten unknown power quantities. Hence, ten equations are needed to solve the system. These quantities and equations are not shown here and reference is made to [9]. Three of the ten equations are utilizing the power control parameters $\Phi$ and $\varphi$ as well as the flight performance. The other equations give the power balance for each of the seven powertrain components. In order to create a balance between the incoming and outgoing power quantities of a component, the corresponding component efficiency $\eta_{\text {comp }}$ is specified, see equation (13). Table 4 gives an overview of the component efficiencies used in this study. The linear system of equations created is finally solved by entering the flight performance requirement for each flight phase. As a result, the required power of the individual components is calculated for each phase:

$$
\mathrm{P}_{\text {out }}=\eta_{\text {comp }} \cdot \sum P_{\text {in }}
$$

On the basis of these calculated power parameters, the component weights for the motors, power electronics, etc. are finally calculated using the specific power values SP and sized to the maximum power. The values used for each individual component are also listed in Table 4:

$$
\mathrm{m}_{\text {comp }}=\frac{\mathrm{P}_{\text {comp, max }}}{\mathrm{SP}_{\text {comp }}}
$$

The model of de Vries does not consider fuel cell systems as an electrical energy source. To make this possible, a corresponding model with efficiency and specific power was added. There are two possible architectures with a fuel cell system (see Fig. 5). Either the fuel cell system can completely replace the battery if it is assumed that the correspondingly high power and currents can be provided by the fuel cell, or the fuel cell can be operated in conjunction with the battery, i.e. as an energy source used in parallel. For this it is assumed that the fuel cell provides a constant, maximum power in cruise and is designed for this, while the battery covers the additional peak power, e.g. in vertical climb or hover. The weight of the fuel cell is also calculated using the specific power. Furthermore, the fuel cell cooling system is assumed to be $50 \%$ of the mass of the fuel cell.

In contrast to the components mentioned above, the mass calculation of the fuel $m_{\text {fuel }}$ or the hydrogen $m_{\text {hydrogen }}$ is not based on the power, but on the energy requirement. In addition to the required power, the duration of the respective output is determined via the mission profile. The specific energy for kerosene $\mathrm{SE}_{\text {fuel }}$ or for hydrogen $\mathrm{SE}_{\mathrm{hydrogen}}$ is $\mathrm{used}$ for the calculation (see Table 4):

$$
\begin{gathered}
\mathrm{m}_{\text {fuel }}=\frac{\mathrm{E}_{\text {fuel }}}{\mathrm{SE}_{\text {fuel }}} \\
\mathrm{m}_{\text {hydrogen }}=\frac{\mathrm{E}_{\text {hydrogen }}}{\mathrm{SE}_{\text {hydrogen }}}
\end{gathered}
$$

The influence of the reduction of the fuel or hydrogen mass over the mission is neglected in the model, since these masses are rather small compared to other component masses in the multirotor design.

The calculation of the battery mass $m_{\text {bat }}$ is based on both the power and the energy requirement and thus differs from the other components of the electric powertrain. The battery mass is determined from the maximum value of both requirements. For this reason, the battery efficiency $\eta_{\text {bat }}$, the minimum and maximum depth of discharge and the $\mathrm{C}$-rate are considered. The C-rate is the current with which a battery is charged and discharged, related to the battery capacity. Other parameters such as the State of Charge (SoC) or the system voltage have been neglected in this design model for the sake of simplicity:

\section{Model for Other Systems}

$$
\mathrm{m}_{\mathrm{bat}}=\max \left(\frac{\mathrm{P}_{\mathrm{bat}, \mathrm{max}}}{\mathrm{SP}_{\mathrm{bat}}}, \frac{\mathrm{E}_{\mathrm{bat}}}{\mathrm{SE}_{\mathrm{bat}}}\right)
$$

While various powertrain architectures can be considered and calculated, the other systems such as flight controls, avionics, instrumentation, furnishings and environmental control system are combined in a general model that was taken from [18]:

$$
\mathrm{m}_{\text {other,sys }}=0.0239 \cdot \mathrm{m}_{\mathrm{MTOM}^{+}}+195.71
$$


This model requires the MTOM as an input variable. It should be noted that the model works with the unit $\mathrm{lb}$ and therefore the input and output values must be converted into the unit $\mathrm{kg}$. In the future, the modeling of these onboard systems is to be improved, for example by considering the systems as mission-dependent, electrical loads when designing the powertrain. Further models for determining mass can be found in [19].

\section{Structure Mass Estimation Model}

In addition to the systems, the structural masses must also be estimated for the dimensioning of the multirotor. Equations for mass estimation for wings, empennage, rotor and hubs, as well as landing gear and fuselage can be found in [19]. However, due to the configuration, the masses for the wings and empennage are omitted for the multirotor. In addition to specifying various parameters such as number of rotors, number of wheels, etc., the equations are primarily based on the input variable aircraft mass or thrust, so that the structural masses as well as the system masses change with each iteration.

\section{Design Study}

One goal in the HorizonUAM project is to develop a system concept for an air taxi. As part of different studies, the onboard systems are to be examined in more detail and the findings are to be incorporated as a contribution to the concept. The aim of this contribution is to investigate the impact of different electric powertrain architectures on the multirotor design. This chapter describes the study (section V.A) and presents and discusses the results and findings (section V.B).

\section{A. Study Definition}

\section{TLARs and Mission (Design Point)}

An intra-city use case was defined for the study. The transport task is to carry out on-demand and non-stop flights within the core area and the densely populated areas of a city. Short transport ranges of up to $50 \mathrm{~km}\left(=\mathrm{D}_{\text {req. }}\right)$ between vertiports and vertistops are to be covered at a speed of up to $100 \mathrm{~km} / \mathrm{h}$. The multirotor configuration with 4 seats including a pilot (or autonomous without a pilot) is particularly suitable for this use case. The payload is $90 \mathrm{~kg}$ per person, i.e. a total of $360 \mathrm{~kg}$. Further parameters for the configuration can be found in Table 2 .

Table 2 Multirotor configuration parameters

\begin{tabular}{|l|l|l|}
\hline Parameter & T/A & Value \\
\hline Disk loading & $\mathrm{N}$ & 4 \\
\hline Number of rotors N & $\mathrm{V}_{\text {tip }}$ & $153 \mathrm{~m} / \mathrm{s}(\mathrm{M}=0.45)$ \\
\hline Rotor blade tip speed & $\mathrm{f}$ & $3 \mathrm{~m}^{2}$ \\
\hline Equivalent flat plate area & $\sigma$ & 0.06 \\
\hline Solidity & $\mathrm{C}_{\mathrm{D} 0}$ & 0.01 \\
\hline Profile zero drag coefficient & $\kappa$ & 1.15 \\
\hline Induced power coefficient & $\mathrm{K}$ &
\end{tabular}

The mission profile used in the study is presented in Fig. 4. The mission consists of three cruise segments and starts and ends at vertiports. During the mission the air taxi should start and land at two vertistops. The overall design range is given by the cruise climb, cruise and cruise descent segments. For each mission segment, the allocated flight performance and further definitions are shown in Table 3. For example, the performance in the start and shutdown segment is simply assumed to be $10 \%$ of the cruise performance. To simplify the flight performance calculation, the air density at mean sea level is assumed as $\rho=1,225 \mathrm{~kg} / \mathrm{m}^{3}$. 


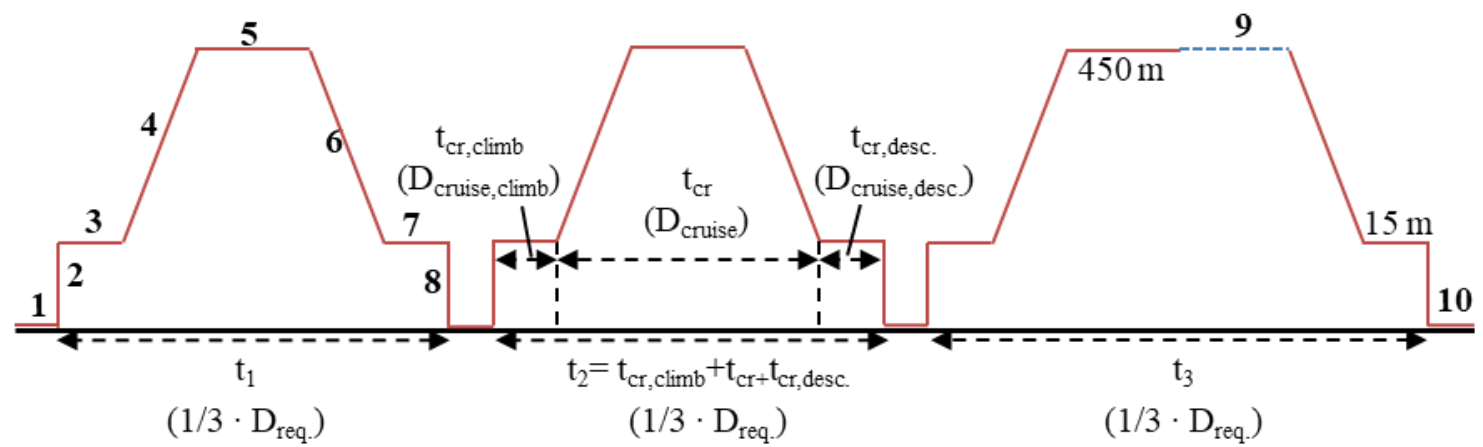

Fig. 4 Mission profile used for sizing of the configurations

Table 3 Mission segment definitions

\begin{tabular}{|c|c|c|c|c|c|}
\hline Segment & Performance & $\begin{array}{c}\text { Cruise } \\
\text { Speed }(\mathrm{m} / \mathrm{s}) \\
\end{array}$ & $\begin{array}{c}\text { Climb } \\
\text { Rate }(\mathbf{m} / \mathbf{s})\end{array}$ & Distance [km] & $\begin{array}{l}\text { Time } \\
(\text { min) }\end{array}$ \\
\hline 1 Start up & $0.1 \cdot \mathrm{P}_{\text {cruise }}$ & - & - & - & 0.3 \\
\hline 2 Vertical Climb & $\mathrm{P}_{\text {climb }}$ & - & 0.5 & - & 0.5 \\
\hline 3 Transition & $\mathrm{P}_{\text {hover }}$ & $\begin{array}{c}0 \text { to } \\
\mathrm{V}_{\text {cruise,be }}\end{array}$ & - & - & 1 \\
\hline 4 Cruise Climb & $\mathrm{P}_{\text {cruise,climb }}$ & $V_{\text {cruise,be }}$ & 4 & $\mathrm{D}_{\text {cruise,climb }}$ & $\mathrm{t}_{\mathrm{cr}, \mathrm{climb}}$ \\
\hline 5 Cruise & $\mathrm{P}_{\text {cruise }}$ & $\mathrm{V}_{\text {cruise,br }}$ & - & $1 / 3 \cdot D_{\text {req. }}-D_{\text {cruise,climb- }}-D_{\text {cruise,desc }}$ & $t_{c r}$ \\
\hline 6 Cruise Descent & $\mathrm{P}_{\text {cruise,desc. }}$ & $V_{\text {cruise,be }}$ & -4 & D $\mathrm{D}_{\text {cruise,desc. }}$ & $t_{\text {cr,desc. }}$ \\
\hline 7 Transition & $\mathrm{P}_{\text {hover }}$ & $\mathrm{V}_{\text {cruise,be }}$ to 0 & - & - & 1 \\
\hline 8 Vertical Descent & $\mathrm{P}_{\text {desc. }}$ & - & -0.5 & - & 0.5 \\
\hline 9 Loiter (Reserve) & $\mathrm{P}_{\text {cruise, loiter }}$ & $V_{\text {cruise,be }}$ & - & - & 20 \\
\hline 10 Shut down & $0.1 \cdot \mathrm{P}_{\text {cruise }}$ & - & - & - & 0.3 \\
\hline
\end{tabular}

\section{Powertrain Architecture Definition}

For the powertrain, full-electric and hybrid-electric architectures and their impact on the design are examined. Fig. 5 provides an overview of the simplified models of the defined architectures. In addition to two full electric architectures with a battery as an energy source, two hybrid-electric powertrains (serial, parallel) are being investigated. The supplied power ratio is varied for both hybrid electrical architectures $(\Phi=[0.2,0.5,0.8])$, so that a total of six variants can be examined. The higher the value for the supplied power ratio is, the closer the two variants come to the two full electric architectures. For the last two architectures, hydrogen-based fuel cell systems are being investigated as an electrical energy source. In case of "Fuel Cell" no battery is used, while, in case of "Fuel Cell \& Bat", a battery is operated in parallel with the fuel cell system. The system was modeled in such a way that the fuel cell is designed for the cruise power and can also provide this power continuously. The battery, on the other hand, provides the peak power. In order to examine the general feasibility of the concepts, the technology level available today is assumed and considered in the design method. Any technological improvement and its impact on the design are not to be examined in this study. The technology parameters, which represent the state of the art, used in the study for the various components are listed in Table 4. 


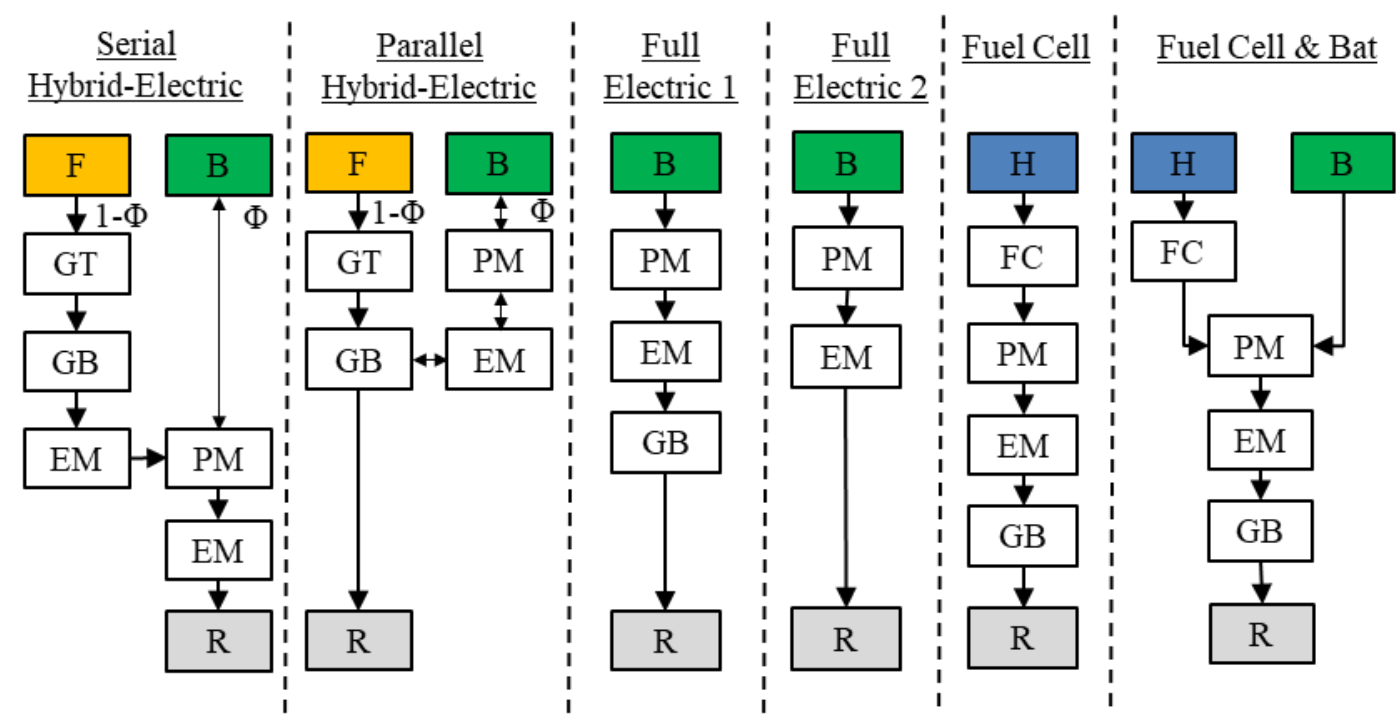
F: Fuel
R: Rotor
B: Battery
PM: Power Management
GB: Gearbox
H: Hydrogen
EM: Electr. Machine/Generator
GT: Gas Turbine
FC: Fuel Cell

Fig. 5 Simplified powertrain models

Table 4 Component technology parameters

\begin{tabular}{|l|c|c|c|}
\hline Powertrain Component & Specific Power & Specific Energy & Efficiency \\
\hline Gas turbine & $8.2 \mathrm{~kW} / \mathrm{kg}$ & - & 0.50 \\
\hline Gear box & $5 \mathrm{~kW} / \mathrm{kg}$ & - & 0.98 \\
\hline Rotors & $3 \mathrm{~kW} / \mathrm{kg}$ & - & $\sim 0.87 *$ \\
\hline Generator & $4 \mathrm{~kW} / \mathrm{kg}$ & - & 0.95 \\
\hline Power Mgmt. & $5 \mathrm{~kW} / \mathrm{kg}$ & - & 0.98 \\
\hline Electr. Motors & $4 \mathrm{~kW} / \mathrm{kg}$ & - & 0.95 \\
\hline Fuel Cell Stack & $0.6 \mathrm{~kW} / \mathrm{kg}$ & - & 0.5 \\
\hline Kerosene & - & $11.8 \mathrm{kWh} / \mathrm{kg}$ & - \\
\hline Hydrogen & - & $33.3 \mathrm{kWh} / \mathrm{kg}$ & - \\
\hline Battery & $625 \mathrm{~W} / \mathrm{kg}$ & $250 \mathrm{Wh} / \mathrm{kg}$ & 0.96 \\
\cline { 2 - 4 } & C-Rate: $2.5 ;$ Useable energy factor: $0.8 ;$ Packaging factor: 0.35 \\
\hline *already considered in the flight performance model \\
\hline
\end{tabular}

\section{Parameter Sweeps and Technology Exploration}

In both previous sections the mission definition and technology parameters, which were used for the calculation of the "references" in the design point, were presented. The analysis of this design point will be carried out in section V.B.1. Next to this, the impact of different design and technology parameter variations on the design is analyzed. An overview of the different parameters, reference values and variations is given in Table 5. 
Table 5 Design and technology parameter variations

\begin{tabular}{|c|c|c|}
\hline Parameter & Reference Value & Variation \\
\hline Design range $\mathrm{D}_{\text {req. }}, \mathrm{km}$ & 50 & $10-120$ \\
\hline Supplied power ratio $\Phi$ & 0.2 & $0.2-1.0$ \\
\hline Disk loading, N/m ${ }^{2}$ & 140 & $100-300$ \\
\hline Battery specific energy, Wh/kg & 250 & $250-700$ \\
\hline Fuel cell specific power, $\mathrm{kW} / \mathrm{kg}$ & 0.6 & $0.4-2.0$ \\
\hline
\end{tabular}

\section{Evaluation Parameters (Metrics)}

Furthermore, evaluation parameters were chosen, which are used to compare the different concepts and to determine the concepts' impact on the design. These parameters are:

- Maximum take-off mass (MTOM) in kg

- Group mass fractions in \% (respectively $\mathrm{m}_{\text {Group }} / \mathrm{MTOM}$ )

- Required gross power-to-weight ratio (respectively reciprocal power efficiency) in W/kg

- Energy intensity or reciprocal energy efficiency (for the nominal mission without reserves) in $\mathrm{Wh} /(\mathrm{PAX} \cdot \mathrm{km})$

\section{B. Study Results Analysis}

In this section, the results of the studies carried out are analyzed using the evaluation parameters. This is initially done for the design point (see section V.A.1). Then, the results are discussed with regard to the parameter variations on the basis of the state-of-the-art system technology. In the last step, the results from the exploratory technology study are presented.

\section{Design Point Analysis}

\section{Maximum Take-off Mass}

Fig. 6 shows the maximum take-off mass for the examined hybrid-electric and full-electric powertrains. Basically, it can be stated that a solution could be found for every configuration on the basis of the defined study (the convergence criterion was met). All solutions are also below the maximum allowable take-off mass of $3,175 \mathrm{~kg}$. The lowest aircraft mass can be found with the two hybrid-electric architectures and a low power ratio $\Phi$. The higher the supplied power ratio, the higher the aircraft weight. The full electric battery systems are the heaviest in this design point.

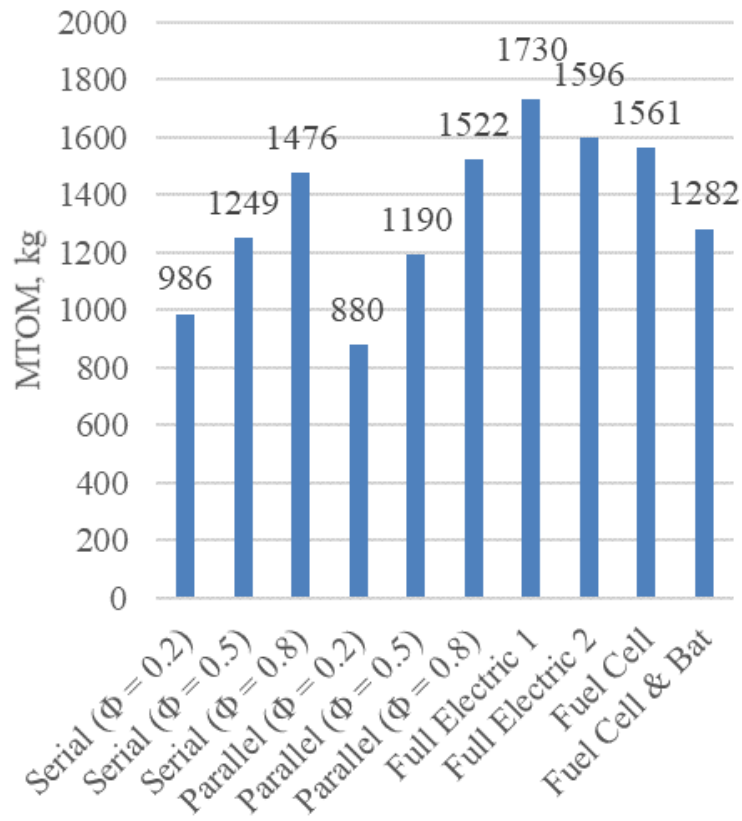

Fig. 6 Maximum take-off mass

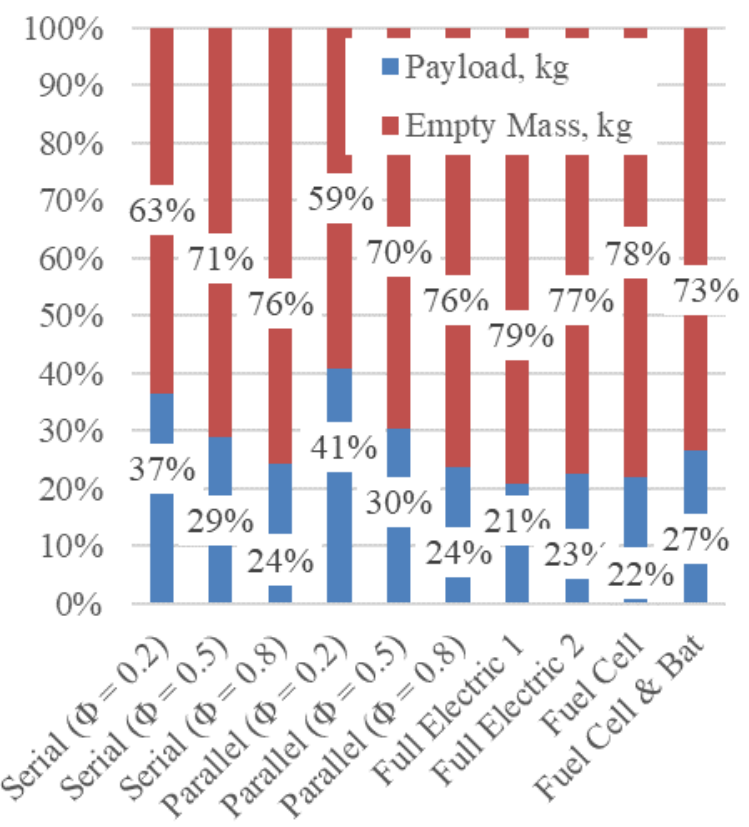

Fig. 7 Empty mass and payload fraction 
Fig. 7 shows the empty mass and payload fractions for the various systems. Although the absolute value of the payload is constant at $360 \mathrm{~kg}$, the relative share decreases as the power ratio increases. The lowest proportion of the payload can also be observed for the full-electric powertrain systems with batteries and fuel cells.

In order to be able to better understand the composition of the aircraft empty mass, Fig. 8 shows the mass groups of structure, energy, powertrain, and other systems of the multirotor and their mass percentages of the total mass. The respective sum corresponds to the empty mass fraction in Fig. 7.

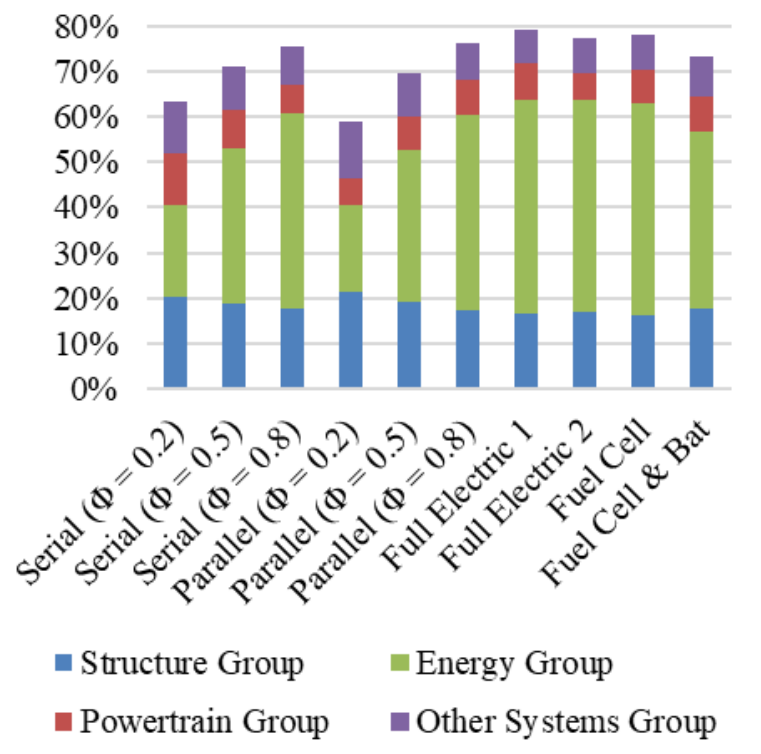

Fig. 8 Mass fractions of the different groups

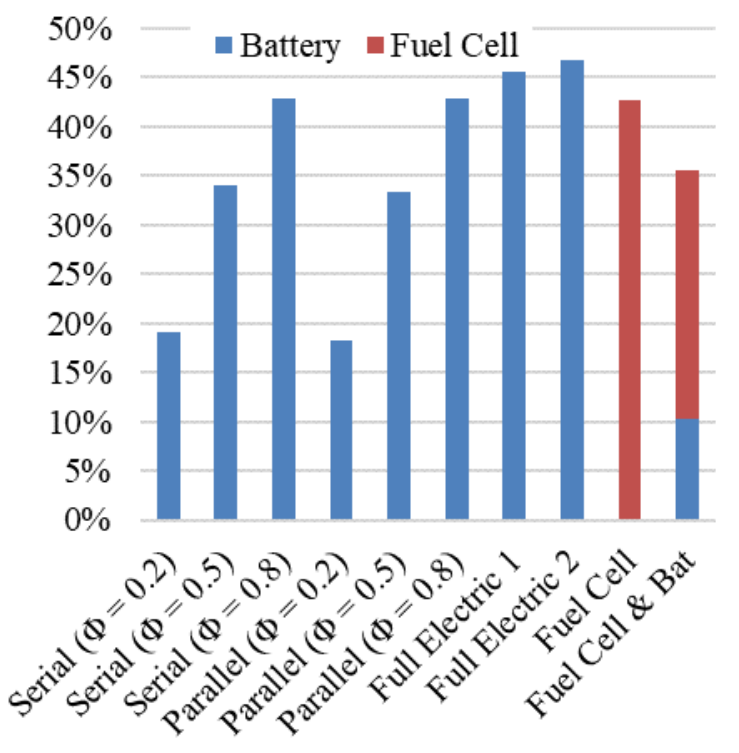

Fig. 9 Battery and fuel cell mass fractions

To determine the group masses, the masses of the individual components were calculated according to the models described in section IV.B. The assignment of the components to the groups was carried out as follows:

- Structure Group: Fuselage, landing gear and rotors (the multirotor does not have wings or empennages)

- Powertrain Group: Electrical machines, gearboxes, power management, gas turbine

- Other Systems Group: Flight controls, avionics, furnishings and anti-icing

- Energy Group: Battery, fuel, fuel cell incl. thermal management, hydrogen and hydrogen tank

Fig. 8 shows that the largest mass fraction variation is in the energy group. The mass fractions of the other groups, on the other hand, vary only slightly. The fraction increases with increasing power ratio, i.e. if more energy is provided from the battery. The full-electric systems therefore have the highest mass fractions in the energy group, as well as the fuel cell systems.

The battery mass can make up a very large proportion of the aircraft empty mass due to its low specific energy. Fig. 9, showing the mass fractions of the battery and the fuel cell system, confirms this. The mass fractions of kerosene and hydrogen are very low compared to the battery and fuel cell and were thus neglected. As can be seen, the increasing empty mass and thus the total mass can be assigned to the impact of the battery mass or the fuel cell system. If a lower MTOM or a higher payload ratio needs to be achieved, the design driver is the battery mass or respectively the fuel cell system.

\section{Required Power and Energy Efficiency}

The different multirotor configurations were also analyzed with regard to their power and energy requirements as well as their power and energy efficiencies. Based on the initial MTOM and the design mission, the required net power can be calculated for each flight segment. In order to calculate the required gross power from the energy sources, one must determine the total powertrain efficiency with the efficiency of the various powertrain components (see Table 4). In the case of hybrid-electric architectures, the supplied power ratio $\Phi$ was also used. In the case of the "Fuel Cell \& Bat" architecture, the efficiency was determined for each flight phase, as the ratio of power to total power (of both energy sources) and thus the efficiency changes. The resulting net and the required gross power, where the latter was determined on the basis of net power and overall powertrain efficiency, are shown in Fig. 10 for the example of a fullelectric powertrain architecture (Full Electric 1). Thereby, the sequence of the different power levels corresponds to the mission segments, which were illustrated in the mission profile in Fig. 4. 


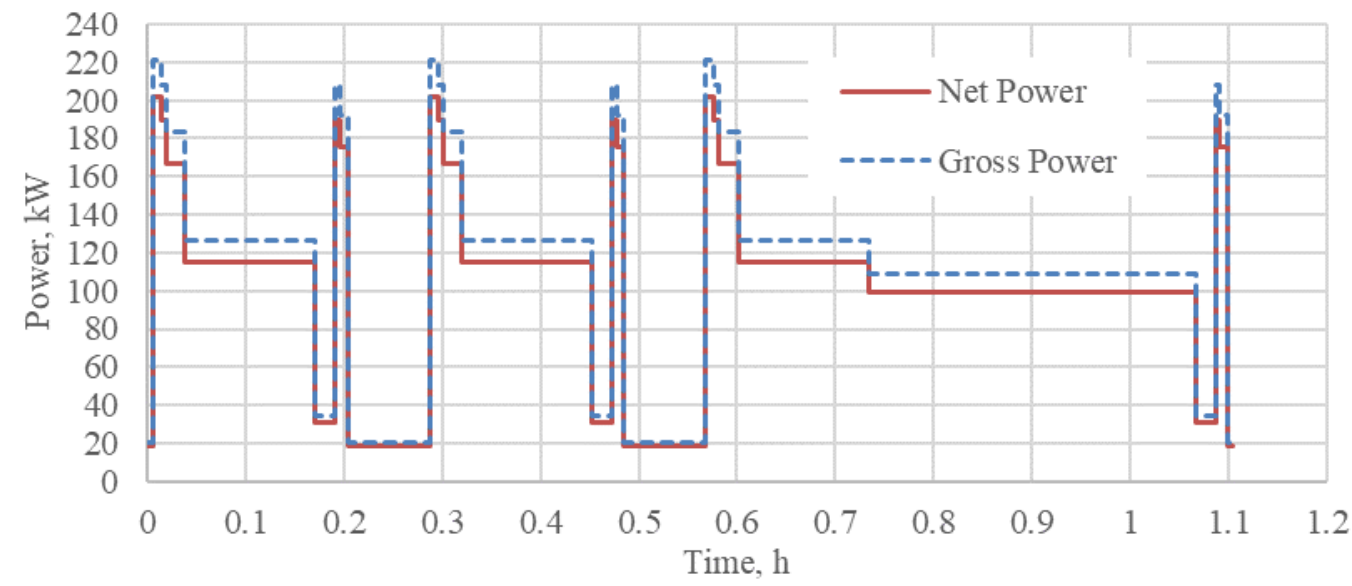

Fig. 10 Aerodynamically required power (net power) and required gross power for the multirotor configuration with full-electric, battery powered architecture (Full Electric 1)

For a better comparison of the configurations with different powertrains, the power-to-weight ratio was calculated as weight-independent parameter for the power efficiency. A distinction can be made in the net power-to-weight ratio and the gross power-to-weight ratio. In this work, a comparison of the gross power-to-weight ratio in hover is accomplished. The power-to-weight ratio is the reciprocal of the power efficiency. The lower the ratio, the less power is required for hover and the higher is the power efficiency of the powertrain. The results for the gross power-toweight ratio for all powertrains is shown in Fig. 11. The full-electric architecture, which also has the highest overall efficiency of all powertrains, has the lowest power-to-weight ratio, respectively the highest power efficiency. The lower the powertrain efficiency, the lower the power efficiency of the powertrain. The fuel cell-based architecture has the lowest power efficiency, which means that this architecture requires more power per kilogram than the other architectures.

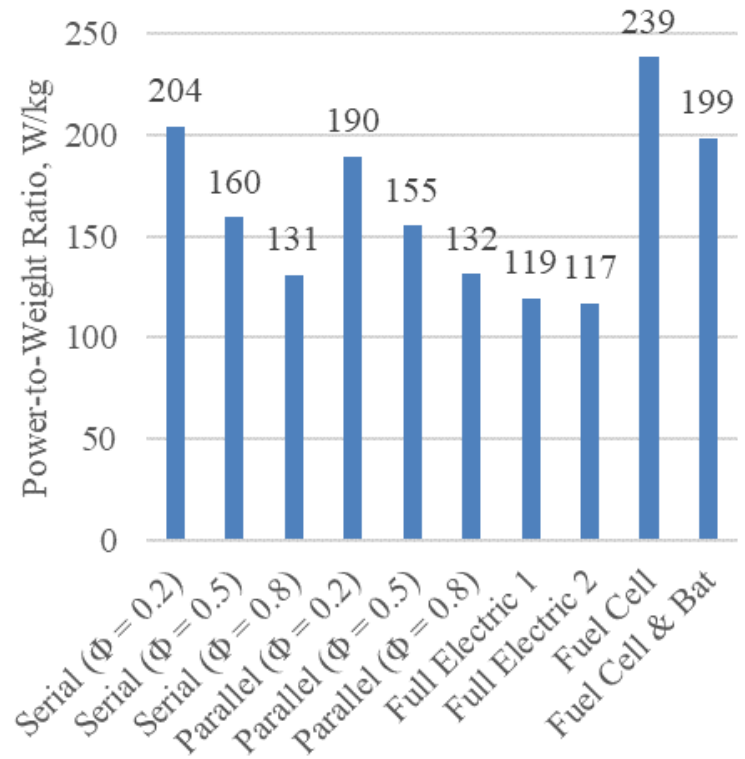

Fig. 11 Gross power-to-weight ratio (hover) as a metric for the reciprocal power efficiency

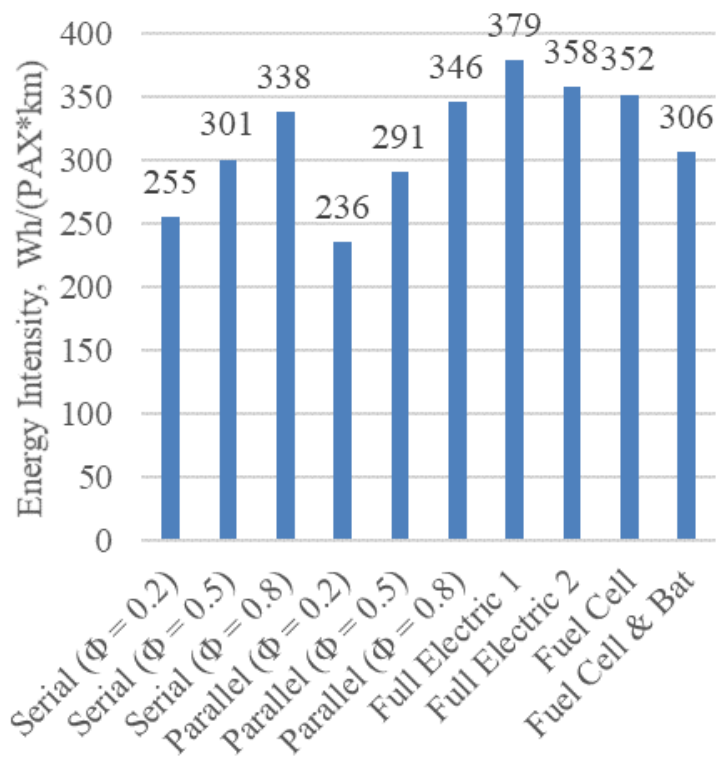

Fig. 12 Nominal mission energy intensity for the design point with $50 \mathrm{~km}$ and four passengers

To calculate the consumed energy, the duration of each flight phase had to be calculated. This duration depends on the mass-dependent cruise speeds (see equations (11) and (12)) and other specifications from Table 3 and the mission profile (Fig. 4). With the gross power and flight phase duration, the energy requirement of each flight phase and thus the total energy consumption for the entire mission could be determined. Using the number of passengers 
and kilometers traveled, the energy intensity in the metric $\mathrm{Wh} /(\mathrm{PAX} * \mathrm{~km})$ was calculated for the nominal mission without any reserves (loiter segment). The energy intensity is the reciprocal of the energy efficiency. The lower the value, the less energy is required for carrying the payload and fulfilling the mission and the more energy-efficient is the configuration.

The calculated energy intensities for each configuration are shown in Fig. 12 for the design range of $50 \mathrm{~km}$ and four passengers. Hybrid-electric architectures show the lowest intensity and thus the best energy efficiency when they have a low supplied power ratio $\Phi$. The higher $\Phi$, the more inefficient the architecture becomes. Full-electric architectures based on battery or fuel cell systems require more energy and are thus the most energy inefficient architectures. The energy efficiency correlates directly with the MTOM. The higher the MTOM, the more energy is required and the less inefficient is the configuration.

\section{Parameter Sweeps}

In this section, the study results for varied parameters will be presented. Parameter variations were made for the design range, the supplied power ratio $\Phi$ and the disk loading. All other parameters, especially system technology parameters, remain the same. The study goal was to better understand the impact of these parameters on the design.

\section{Design Range}

Based on the defined design mission, the required design range $\mathrm{D}_{\text {req. }}$ was varied between 10 and $120 \mathrm{~km}$. Fig. 13 shows the results for selected electric powertrain architectures. In comparison, the configurations with hybrid-electric architectures in combination with a low $\Phi$ have the lowest MTOM over the examined range. A slight, increase in MTOM can be seen over the range. For the full-electric configurations, however, an exponential much stronger increase in MTOM can be observed. Based on the given design requirements, a maximum design range of approx. $100 \mathrm{~km}$ is possible before the allowed MTOM according to SC-VTOL is exceeded. Below the design range of $50 \mathrm{~km}$, the architecture has advantages against fuel cell-based architectures. For the configuration with battery and fuel cell system (Fuel Cell \& Bat), an almost constant MTOM can be seen. The very small linear increase of MTOM can be attributed to the additional energy required with increasing design range. This leads to a higher amount of hydrogen which is ultimately reflected in a slightly higher MTOM. From a range of around $25 \mathrm{~km}$, this variant is lighter than the full-electric powertrain (Full Electric 1), and from around $120 \mathrm{~km}$ the MTOM is roughly equivalent to that of hybrid-electric variants. With the purely fuel cell-based configuration, a very small increase in MTOM can also be seen over the range. From a range of around $40 \mathrm{~km}$, this architecture has a lower MTOM than the full-electric architecture. It can be seen from the figure that, in principle, any powertrain architecture could be applied for the multirotor up to a range of around $100 \mathrm{~km}$. Hybrid-electric or full-electric architectures with battery systems are advantageous for shorter ranges; fuel cell-based systems are more advantageous for longer design ranges. In particular, the configuration with a full-electric powertrain could reach its allowable mass limits for longer design ranges.

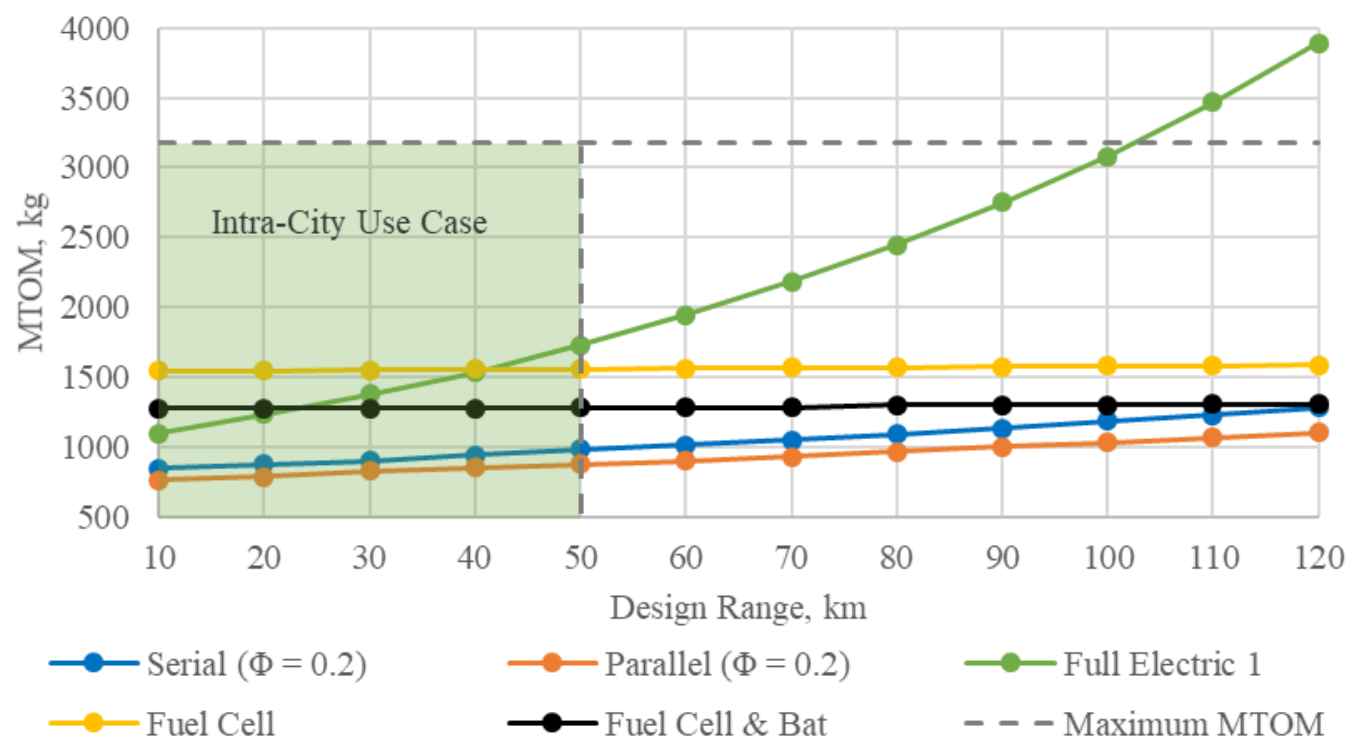

Fig. 13 MTOM of eVTOL with different powertrain architectures and for different design ranges 
From the previous investigation it is known that the energy group has a decisive influence on the MTOM. In order to analyze this influence over the design range, Fig. 14 shows the group mass fractions for the different design ranges taking the example of the full-electric powertrain architecture (Full Electric 1). Here, the increase in the mass fraction of the energy group from around 30\% (10 km) to around 65\% (at $120 \mathrm{~km}$ ) for the full-electric variant can be determined while the other mass fractions, especially the payload ratio, decrease. Fig. 15 shows the mass fraction of the energy group for the different architectures. Especially the architectures with batteries (i.e. full-electric, hybrid-electric) show a strong increase in the mass fraction. The fuel cell-based architecture, on the other hand, remains nearly constant.

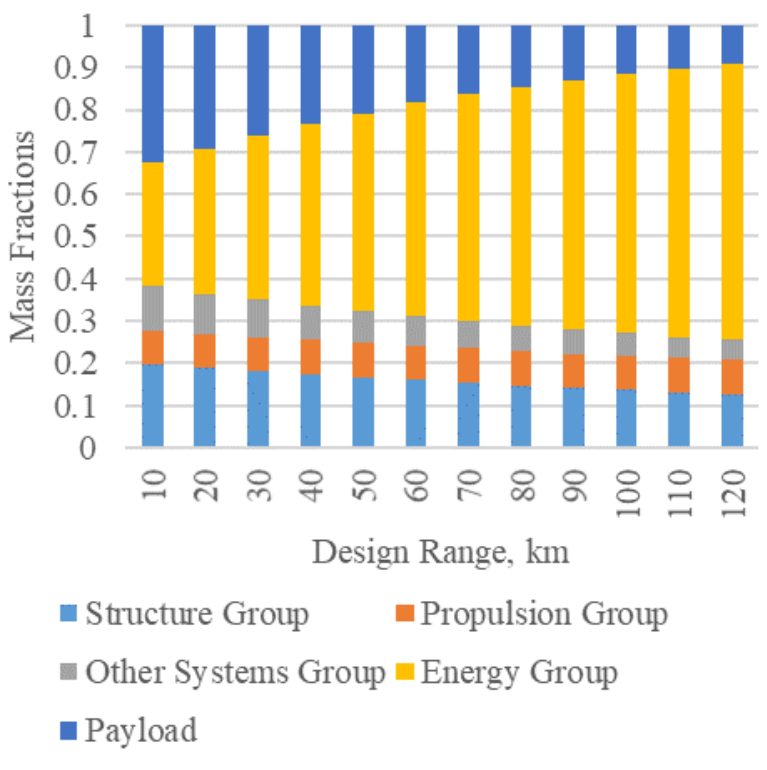

Fig. 14 Group mass fractions of eVTOL with fullelectric powertrain architecture (Full Electric 1)

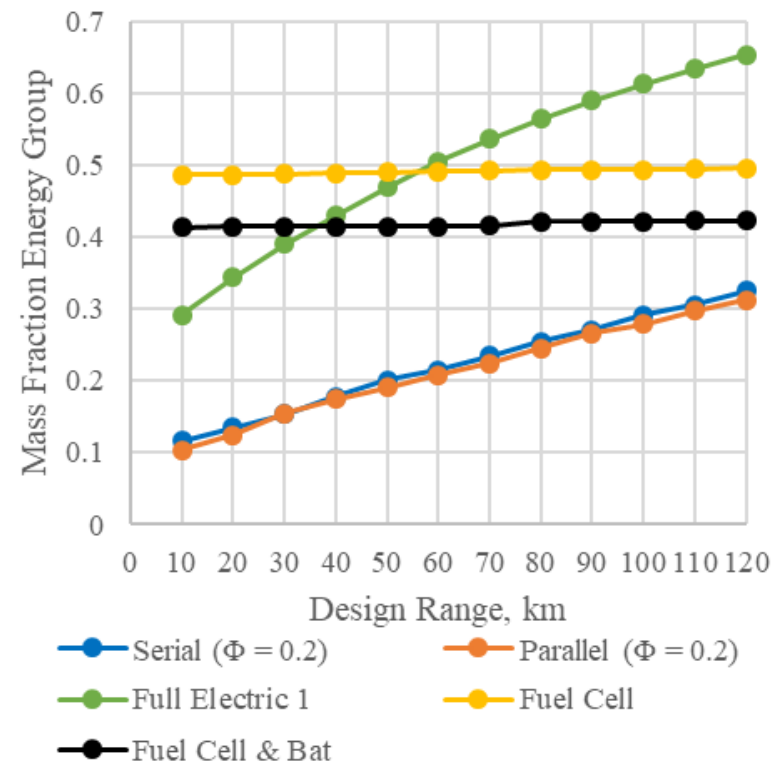

Fig. 15 Energy group mass fractions for eVTOL with different powertrain architectures

Fig. 16 shows the required gross power-to-weight ratio in hover for the various powertrain architectures and design ranges. No sensitivities to the design range can be observed here. The results correspond to the results already discussed in the design point analysis. The higher the overall efficiency of the powertrain, the more power-efficient the variant.

Fig. 17 shows the nominal energy intensity of the various powertrains over the design ranges. Basically, a distinction between the architectures can be seen here. Fuel cell-based architectures show an exponentially decreasing trend in energy intensity, i.e. the higher the range, the more energy-efficient these architectures will become. The variant with fuel cell and battery is more efficient than the pure fuel cell architecture. The hybrid-electric powertrain architecture also shows an exponentially decreasing trend up to around $70 \mathrm{~km}$ and then a slight increase follows. This means that these systems are more energy-inefficient at shorter design ranges up to around $70 \mathrm{~km}$ than at longer ranges. However, in comparison to the other variants these architectures are the most energy-efficient. The full-electric architecture shows a very strong decrease in energy intensity up to about $40 \mathrm{~km}$, where an optimum for the energy efficiency of this variant lies. After this optimum, a sharp increase in the energy intensity can be seen, and thereby a decrease in efficiency. From a range of $40 \mathrm{~km}$, this architecture is the most inefficient in comparison to the other architectures. However, at the reference design range of $50 \mathrm{~km}$, this architecture's efficiency is still acceptable. 


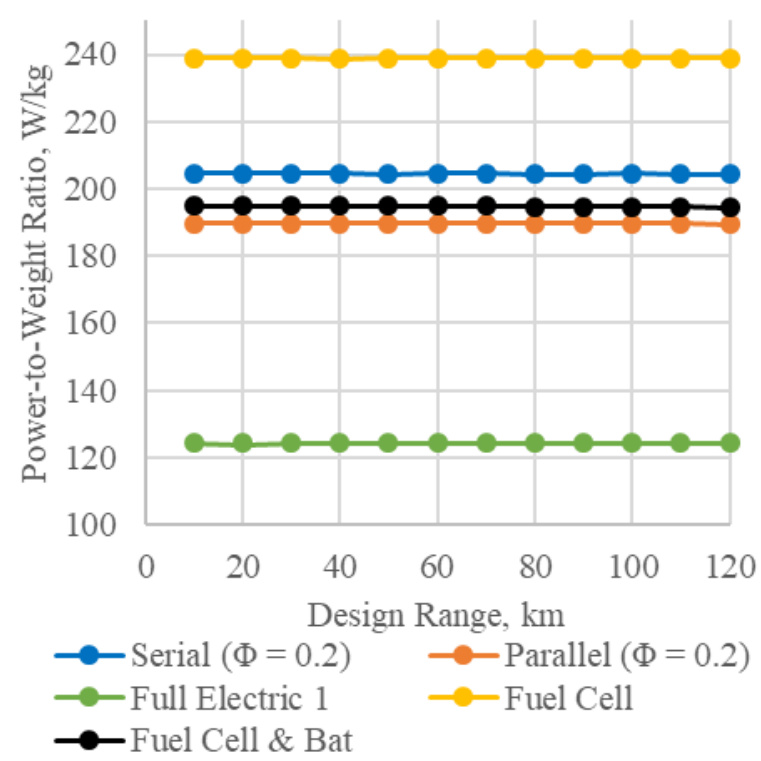

Fig. 16 Required gross power-to-weight ratio (hover) for different design ranges and powertrain architectures

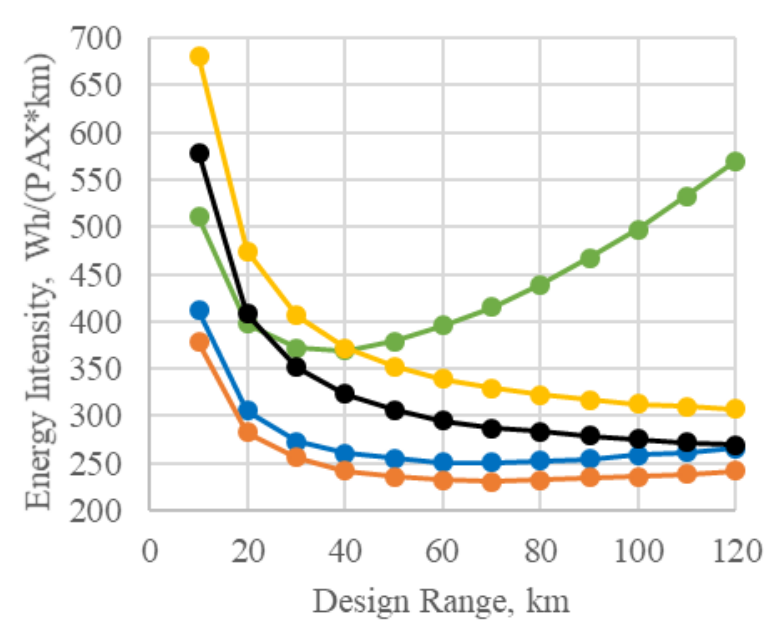

$\longrightarrow$ Serial $(\Phi=0.2) \quad \longrightarrow$ Parallel $(\Phi=0.2)$
$\longrightarrow$ Full Electric $1 \quad \longrightarrow$ Fuel Cell
$\longrightarrow$ Fuel Cell \& Bat

Fig. 17 Nominal mission energy efficiency for different design ranges and powertrain architectures

\section{Supplied Power Ratio $\Phi$}

The influence of the supplied power ratio $\Phi$ is analyzed in more detail. The higher the supplied power ratio $\Phi$, the more energy is provided by the battery. Fig. 18 shows the MTOMs determined for the various design ranges using the example of the parallel hybrid-electric architectures with different $\Phi$. Serial hybrid-electric architectures show a similar behavior. For all variants, an exponential increase in MTOM can be observed with increasing design range, which is caused by the increasing battery mass. The absolute values as well as the increases depend on $\Phi$. The higher $\Phi$, the higher the MTOM and the increase. The curve profile of MTOM for $\Phi=1.0$ corresponds here to the curve profile of the full-electric architecture from Fig. 13. These results also coincide with the design point analysis, which showed that the MTOM increases with higher $\Phi$. For a low MTOM, which leads to a higher payload ratio, a hybridelectric architecture with a low $\Phi$ should be selected.

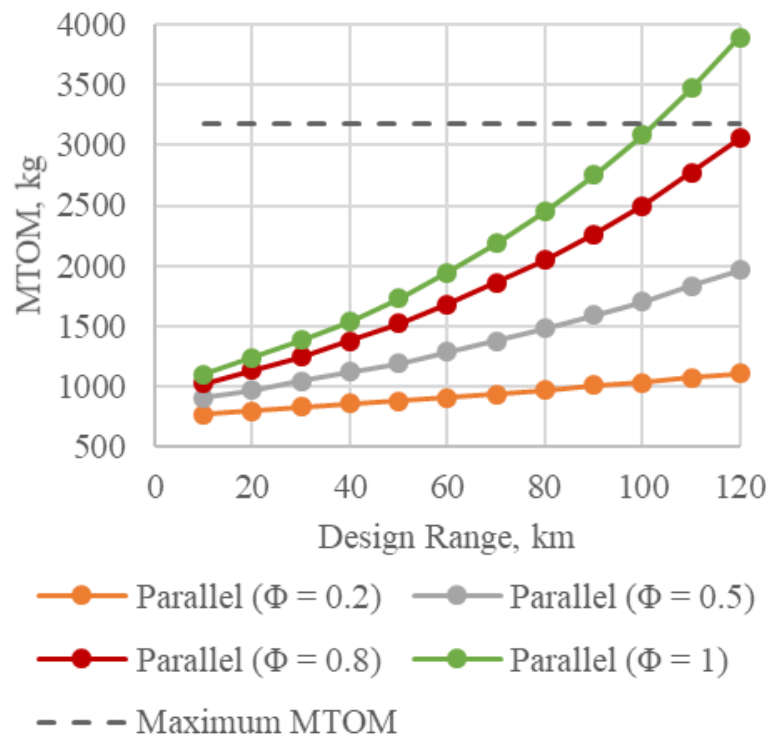

Fig. 18 MTOM for different $\Phi$ and design ranges using the example of parallel hybrid-electric architectures 
Fig. 19 shows the gross power-to-weight ratio in hover for the various parallel hybrid-electric architectures with different $\Phi$. No sensitivities to the design range can be observed here. The differences arise from different $\Phi$, which result in various degrees of powertrain efficiencies. The higher the $\Phi$, i.e. the proportion of energy that comes from the battery, the higher the efficiency of the powertrain. Due to the already established correlation, the power-to-weight ratio decreases, i.e. the power efficiency increases, with increasing $\Phi$. For a configuration with higher power efficiency, a hybrid-electric architecture with a high $\Phi$ and thus a high overall powertrain efficiency should be selected.

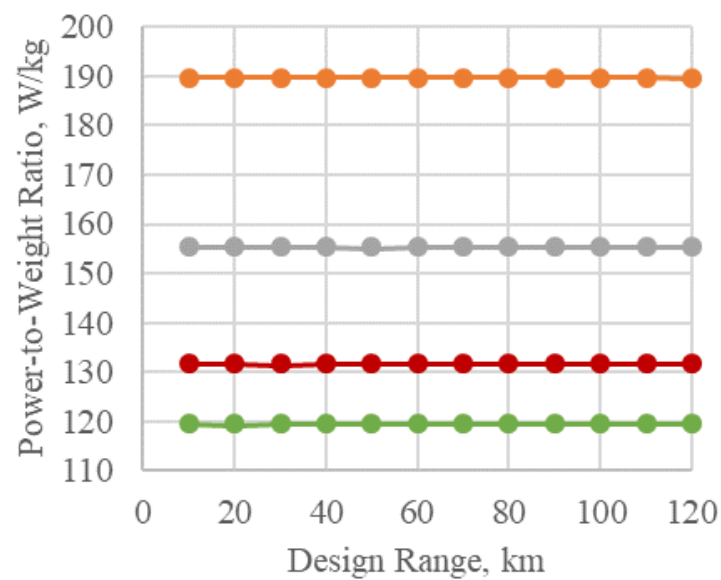

$\longrightarrow$ Parallel $(\Phi=0.2) \rightarrow$ Parallel $(\Phi=0.5)$

$\longrightarrow$ Parallel $(\Phi=0.8) \longrightarrow$ Parallel $(\Phi=1)$

Fig. 19 Required gross power-to-weight ratio (hover) for different $\Phi$ and design ranges (parallel hybridelectric)
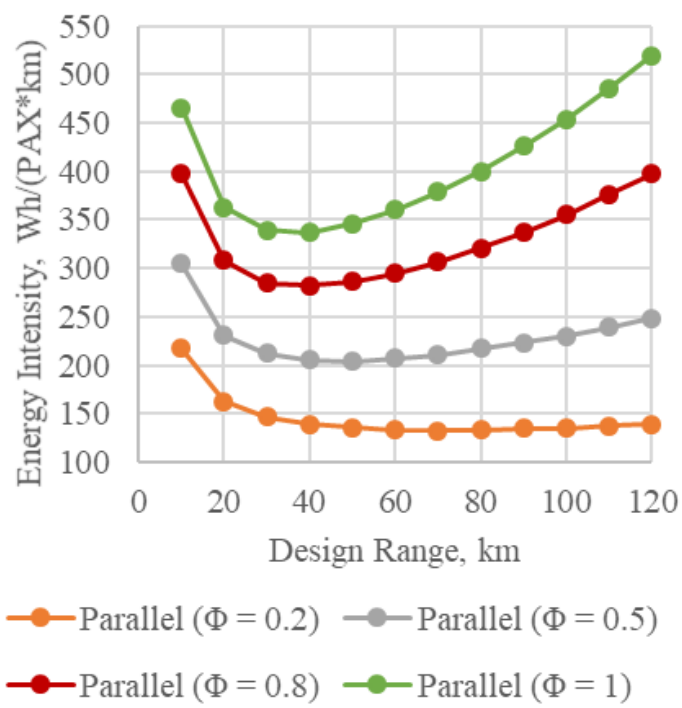

Fig. 20 shows the energy intensity using the example of parallel hybrid-electric architectures with different $\Phi$. The curve for $\Phi=0.2$ coincides with the previous curve from Fig. 17, i.e. showing a decreasing trend up to about 40, depending on $\Phi$, followed by an increasing trend. As $\Phi$ increases, this curve shifts upwards and the slope increases. This means that, with increasing $\Phi$ and increasing design range, the architectures become more energy-inefficient above this point. At the maximum value of $\Phi=1.0$, the greatest slope is reached. This curve course corresponds to the curve of the full-electric architecture (Full Electric 1) from Fig. 17. In addition, the optimum in energy efficiency shifts from around $70 \mathrm{~km}($ at $\Phi=0.2)$ to around $30 \mathrm{~km}($ at $\Phi=1.0)$. An architecture with a low $\Phi$ should be selected for an energy-efficient system. In this case, the amount of energy from the battery would be low, which ultimately leads to a lower MTOM and thus to a lower energy demand.

\section{Disk Loading}

The required disk loading was varied between 100 and $300 \mathrm{~N} / \mathrm{m}^{2}$. It is known from the literature that the hover performance increases with increasing disk loading [16]. With increasing performance, the maximum power for sizing the powertrain components will also increase. Assuming the same component technology level in the sense of $\mathrm{kW} / \mathrm{kg}$ (see Table 4), heavier components will result which is also noticeable in the aircraft mass. This means that, with increasing disk loading, an increase in MTOM can be expected. This increase can be seen in Fig. 21. However, the increase in MTOM is different for the various architectures. The hybrid-electric architectures initially drop very little and reach a minimum at $140 \mathrm{~N} / \mathrm{m}^{2}$. After that, a moderate increase in MTOM can be seen $\left(\sim 100 \mathrm{~kg}\right.$ per $\left.100 \mathrm{~N} / \mathrm{m}^{2}\right)$. Full-electric architectures initially drop to a minimum also at around $140 \mathrm{~N} / \mathrm{m}^{2}$ and then increase at a higher rate $(\sim 250$ $\mathrm{kg}$ per $100 \mathrm{~N} / \mathrm{m}^{2}$ ). The fuel cell-based architectures are increasing exponentially. The increase in the fuel cell architecture is stronger than that of the hybrid variant (Fuel Cell \& Bat). The curve of the fuel cell architecture is intersected by the curve of the full-electric variant at T/A $=200 \mathrm{~N} / \mathrm{m}^{2}$. This means that the configuration with fuel cell architecture represents the heaviest configuration from a certain disk loading onwards. For the examined disk loading range, the absolute value of MTOM remains below the allowable limit of 3,175 kg for all variants. 


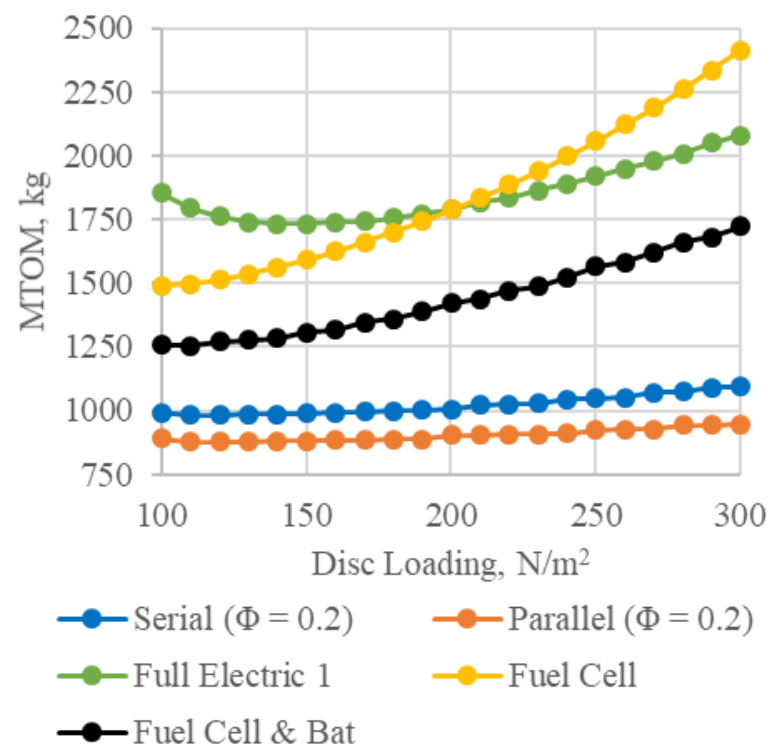

Fig. 21 MTOM for different disk loadings and powertrain architectures

Fig. 22 shows the required gross power-to-weight ratio in hover for the different architectures and disk loadings. A higher disk loading requires a higher hover performance, which in turn results in an increase in the power-to-weight ratio. As expected, the higher the disk loading, the less power-efficient the system becomes. For a higher power efficiency, a lower disk loading should be selected. The increase is similar for all architectures. The absolute depends on the powertrain efficiency $\eta$. The higher the powertrain efficiency is, the less is the power-to-weight ratio and the more power-efficient the architecture is (regardless of the selected disk loading).

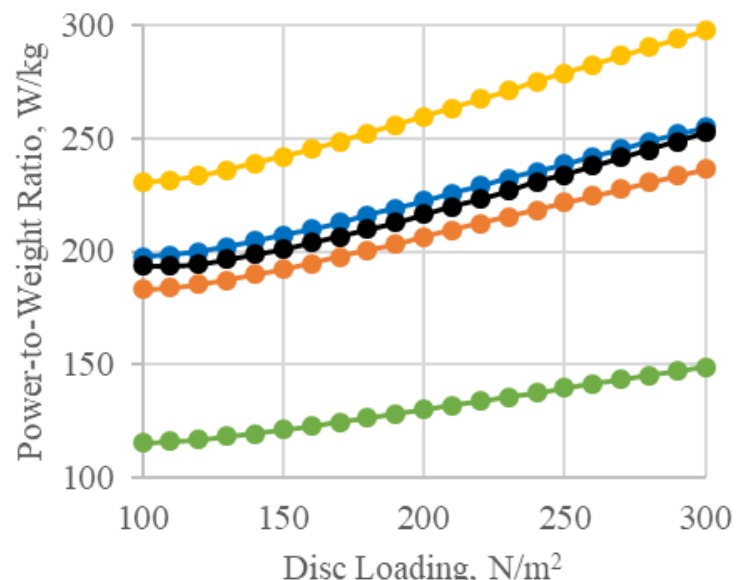

$\rightarrow \operatorname{Serial}(\Phi=0.2) \quad \longrightarrow$ Parallel $(\Phi=0.2)$

$\longrightarrow$ Full Electric 1

$\longrightarrow-$ Fuel Cell

$\longrightarrow$ Fuel Cell \& Bat

Fig. 22 Required gross power-to weight ratio (hover) for different disk loadings

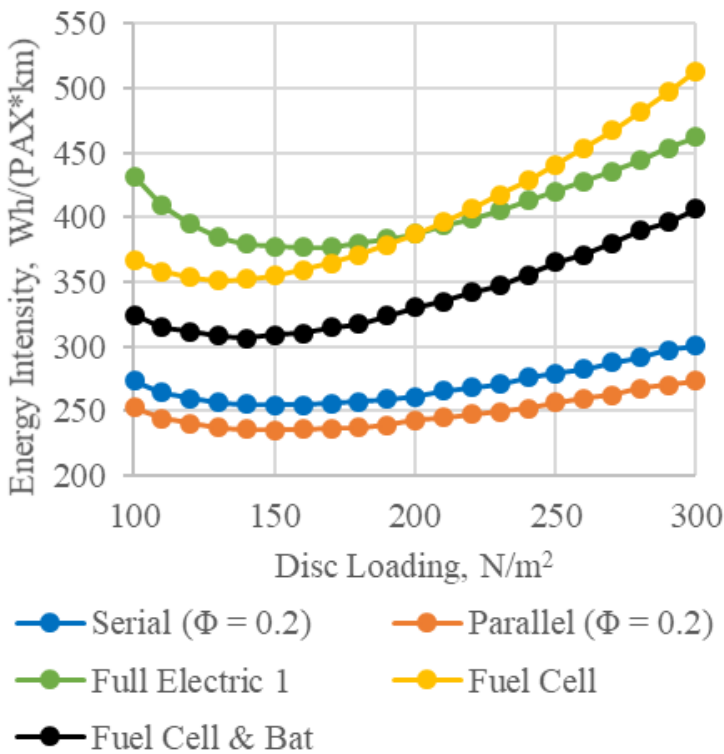

Fig. 23 Nominal mission energy intensity for different disk loadings

The already established correlation between MTOM and energy efficiency can also be observed for the various disk loadings (see Fig. 23). With increasing disk loading, the MTOM increases and thus the energy requirement. The higher the disk loading, the more energy-inefficient the system becomes. As can be seen in Fig. 23, the minimum for the hybrid-electric and full-electric variants is at around $160 \mathrm{~N} / \mathrm{m}^{2}$. The curve intersection between the full-electric and purely fuel cell-based variant is at about $200 \mathrm{~N} / \mathrm{m}^{2}$, i.e. the configuration with fuel cell architecture becomes the 
most energy-inefficient for higher disk loadings. Overall, higher disk loadings lead to more inefficient systems. Therefore, lower disk loadings should be chosen for higher energy efficiency.

\section{Technology Exploration}

In the last step, the results from the exploratory technology study are presented. Therefor the battery specific energy was varied between 250 and $700 \mathrm{Wh} / \mathrm{kg}$, and the fuel cell-specific power was varied between 0.4 and $2.0 \mathrm{~kW} / \mathrm{kg}$. The MTOM results for the configurations with different powertrain architectures can be seen in Fig. 24 and Fig. 25.

As expected, an increase in battery-specific energy, i.e. an improvement in battery technology, leads to a decrease in MTOM (see Fig. 24). The architectures can be distinguished as follows. The full-electric architectures show a very strong exponential decrease. At around 600 to $700 \mathrm{Wh} / \mathrm{kg}$, the level of the parallel hybrid-electric variant with today's technology is reached (blue curve at $250 \mathrm{Wh} / \mathrm{kg}$ ). At a value of around $400 \mathrm{Wh} / \mathrm{kg}$, the curves of the full-electric and the hybrid variant with fuel cell and battery (Fuel Cell \& Bat) intersect, i.e. the hybrid variant becomes the heaviest configuration. With the hybrid-electric as well as the variant with fuel cell and battery, a slight exponential decrease in MTOM can be observed, which is small compared to that of the full-electric configuration. The decreasing trends are very similar. Accordingly, improved battery technology has a greater impact to the MTOM when the architecture takes a large energy ratio from the battery. This means that a full-electric or hybrid-electric architecture with a large $\Phi$ should preferably be used if the use of improved battery technology can be expected in the near future.

An improved fuel cell technology in terms of specific power also leads to a decrease in MTOM (see Fig. 25). A purely fuel cell-based architecture is more sensitive in comparison to a hybrid variant with battery. A very strong exponential decrease can be observed up to about $0.8 \mathrm{~kW} / \mathrm{kg}$. From around $0.8 \mathrm{~kW} / \mathrm{kg}$ on, similar improvements in MTOM can be expected for any of the architectures examined. None of the architectures with fuel cell systems has a clear advantage and a further improvement in the technology does not ultimately result in any major changes.
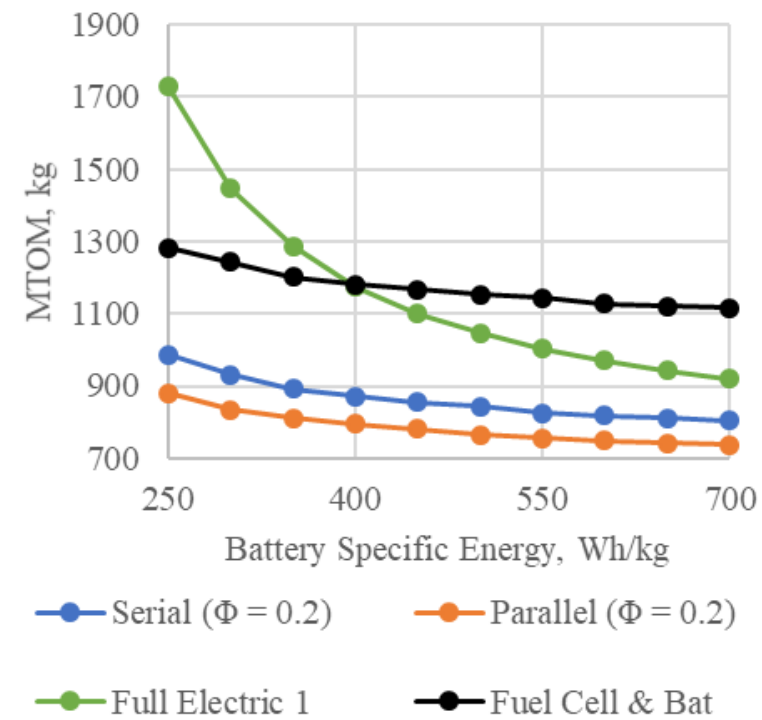

Fig. 24 MTOM for different battery specific energy

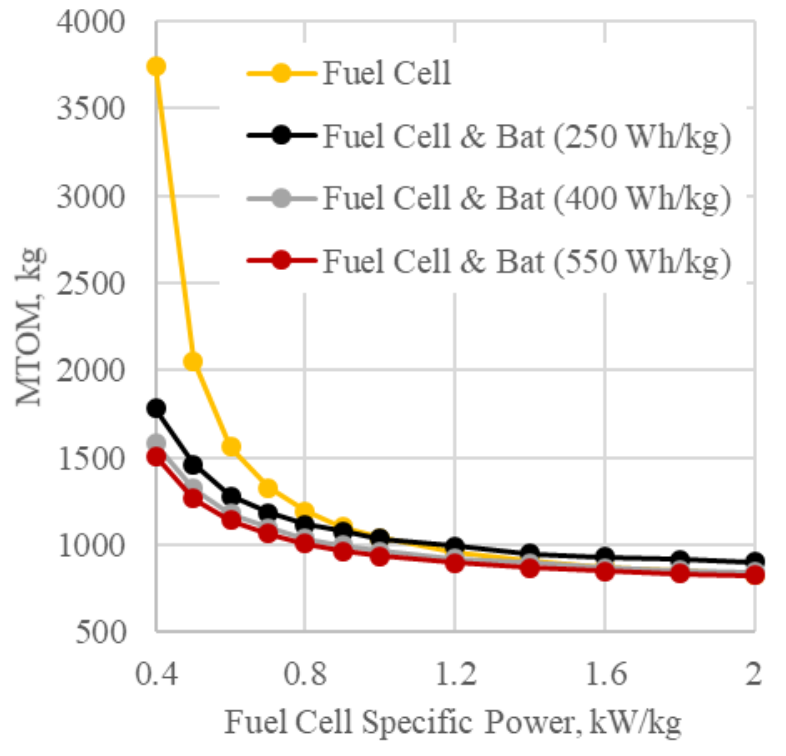

Fig. 25 MTOM for different fuel cell specific power

Fig. 26 shows the gross power-to-weight ratio in hover of the architectures for different battery specific energies. An influence of the battery specific energy on the power efficiency cannot be identified. The improved technology reduces the MTOM, but at the same time the required hover performance decreases in the same ratio. A distinction between the architectures is given by the different powertrain efficiencies. The correlation between the energy intensity and the MTOM can be seen in Fig. 27. The higher the battery specific energy, the less energy is required and the more energy-efficient the system becomes. At around $400 \mathrm{Wh} / \mathrm{kg}$, the configuration with full-electric architecture is more efficient than the hybrid variant with fuel cell and battery (Fuel Cell \& Bat). Above 600-700 Wh/kg, the fullelectric architecture reaches the level of the parallel hybrid-electric architecture with a low supplied power ratio $\Phi$ and today's battery technology (blue curve at $250 \mathrm{Wh} / \mathrm{kg}$ ). The higher the ratio of energy from the battery, the more sensitive the architecture is to the improved battery technology. 

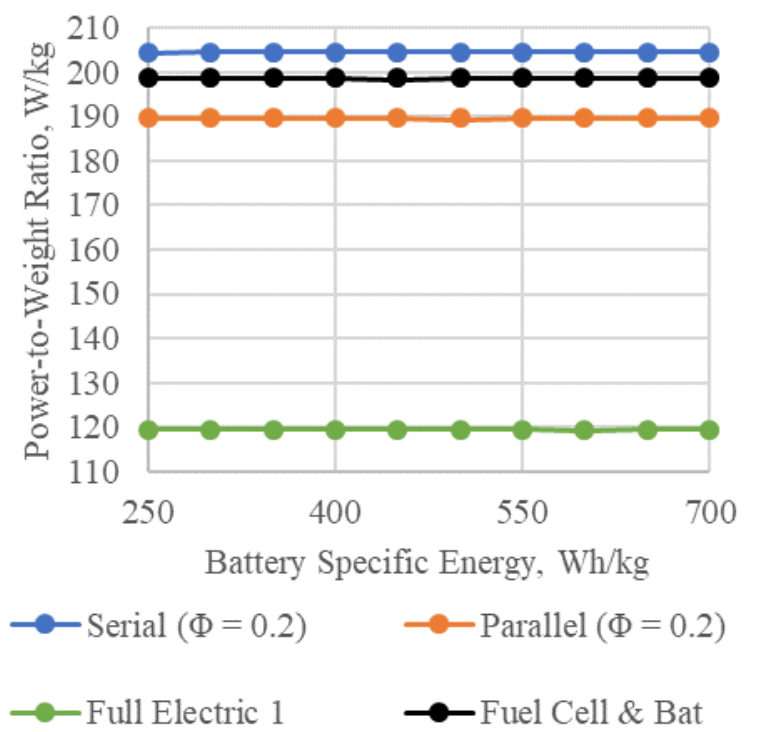

Fig. 26 Required gross power-to weight (hover) for different battery specific energy
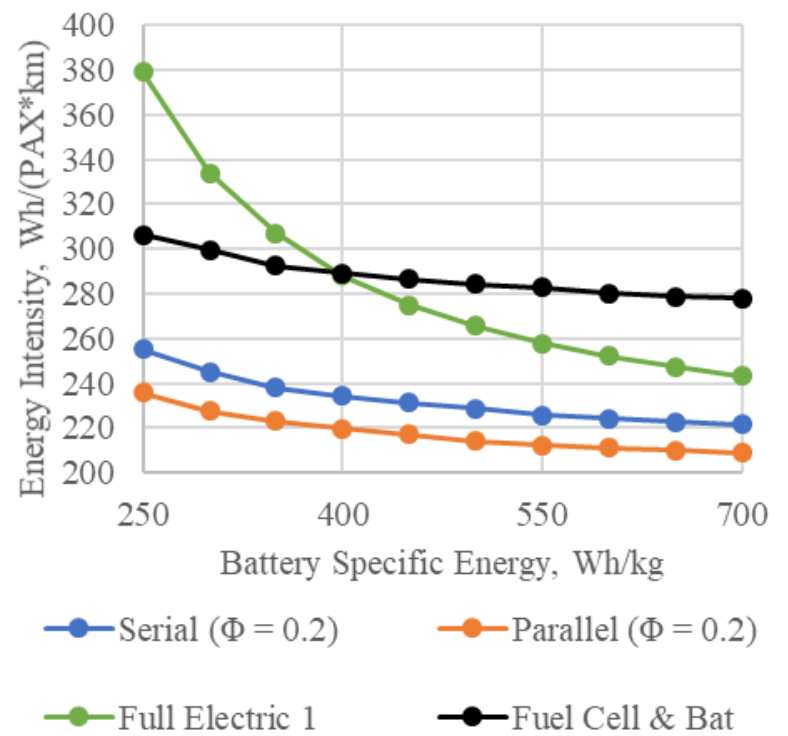

Fig. 28 shows the gross power-to-weight ratio in hover of the architectures for different fuel cell specific powers. There is no direct influence of the various specific powers on the power efficiency in hover. Due to the low level of powertrain efficiency, the purely fuel cell-based variant is more power-inefficient than the variants with fuel cell and battery. The hybrid variants are similarly efficient regardless of the battery technology.

Fig. 29 shows the energy intensity of the various architectures for different fuel cell specific powers. The correlation to MTOM can also be seen here (see Fig. 25). All configurations have a similar efficiency above $0.8 \mathrm{Wh} / \mathrm{kg}$. However, the energy efficiency increases as the technology level of the fuel cell rises.

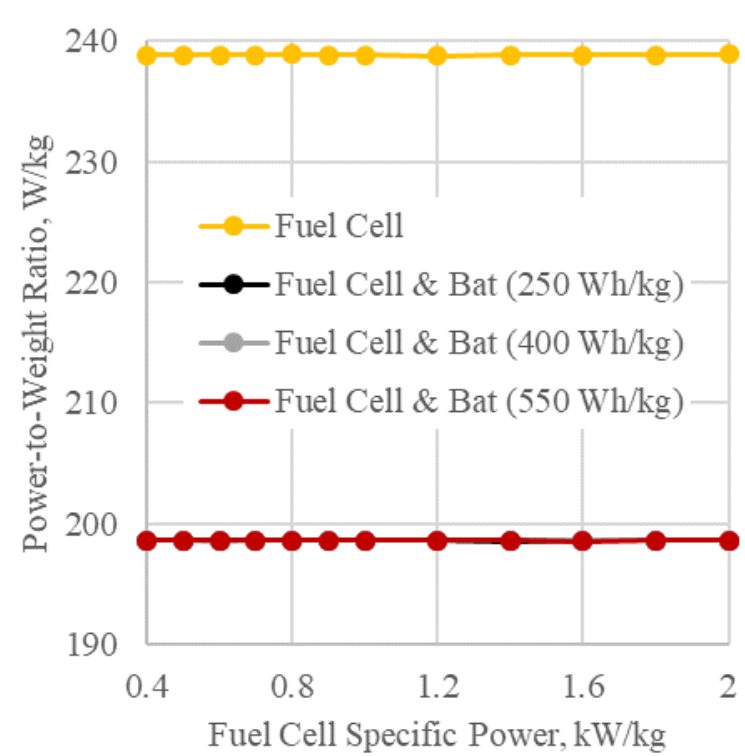

Fig. 28 Required gross power-to weight (hover) for different fuel cell specific power and battery specific energy

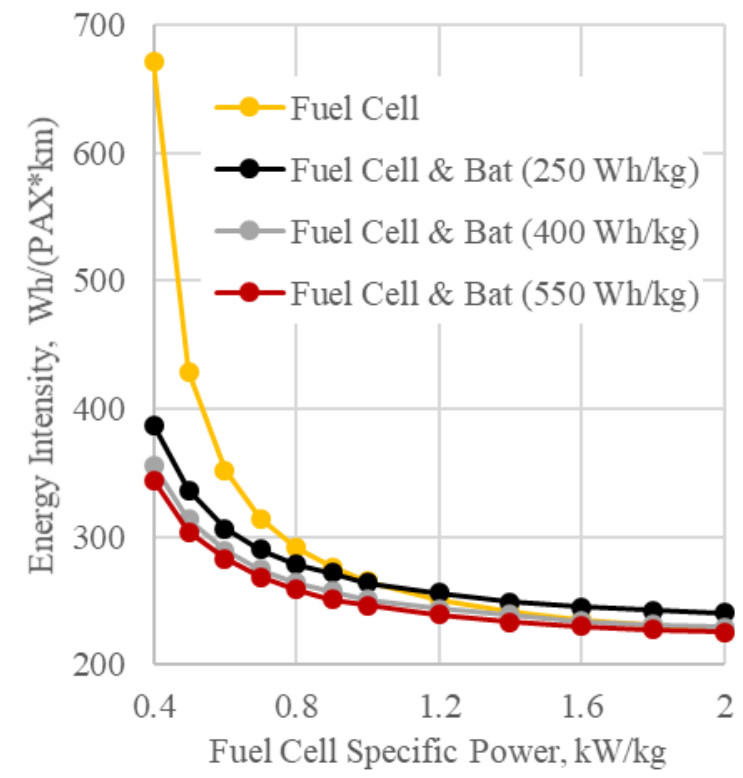

Fig. 29 Nominal mission energy intensity for different fuel cell specific power and battery specific energy 


\section{Final Evaluation}

Within the presented study, parameter sweeps and technology exploration were performed and different powertrain architectures were examined in more detail based on a simple, generic and sizeable multirotor configuration. In the following, the presented results are used to answer the key questions from Chapter II.

\section{What is the impact of different electric powertrain architectures on the eVTOL design? Which powertrain architecture should best be chosen for which mission?}

It could be shown that the battery and respectively the fuel cell systems as part of the energy group are important design drivers for the MTOM. The lower the MTOM the higher the payload ratio. The results demonstrated that the MTOM depends on the selected design range, the supplied power ratio $\Phi$, the disk loading, as well as the technology levels of e.g. battery and fuel cell systems. The selected powertrain architecture also plays a very important role. With regard to MTOM, it was found that full-electric and hybrid-electric architectures are advantageous for shorter ranges, while architectures with fuel cell systems are more advantageous for longer ranges $(>50 \mathrm{~km})$. In addition, the correlation between MTOM and energy efficiency (of the nominal mission) could be shown. The higher the MTOM, the more inefficient the configuration. Therefore, architectures that have a low MTOM should be selected for an energy-efficient configuration. Powertrain architectures with high efficiency (e.g. full-electric, hybrid-electric with high $\Phi$ ) also show a higher power efficiency (in hover) compared to architectures with lower efficiency (e.g. fuel cellbased or hybrid-electric with low $\Phi$ ). However, it is exactly these architectures that lead to heavy and therefore energyinefficient configurations. To remedy this, the mission requirements must either clearly speak in favor of a light, energy-efficient configuration or a heavy power-efficient configuration. Alternatively, a suitable power management could increase the performance and energy efficiency in different flight phases and thus the overall efficiency of the aircraft. The disadvantages of a pure full-electric solution based on batteries, for instance, could be at least partially reduced. This can be achieved through the use of hybrid-electric solutions (e.g. parallel hybrid-electric, fuel cell and battery). However, these architectures increase the system complexity, costs and maintenance effort, among other things.

\section{What is the impact of the degree of hybridization on different powertrain architectures and the feasibility of an eVTOL concept?}

The supplied power ratio $\Phi$ represents a measure of the battery energy ratio in hybrid-electric architectures. The higher the $\Phi$, the higher the battery ratio, which is reflected in a higher MTOM and lower energy efficiency on the one hand. On the other hand, the overall powertrain efficiency also increases, which leads to higher power efficiency of the configuration. The use of suitable power management, which has already been described above, could prove to be advantageous here.

\section{What is the influence of future battery technology on the eVTOL characteristics?}

The improvement of battery technology, here characterized in terms of battery specific energy, leads to a decrease of MTOM and a resulting improvement of energy efficiency of the configuration. With regard to the power efficiency in hover, no influence could be determined, since the required performance in hover decreases to the same ratio as the MTOM.

What influence does an electric fuel cell architecture have on the entire eVTOL design compared to a batteryelectric architecture?

A configuration with a fuel cell system architecture and today's technology has a lower MTOM than a batteryelectric system and thus a higher energy efficiency. These characteristics can be increased even further by using a hybrid system with fuel cell and battery. A higher design range would be beneficial, as this also increases the energy efficiency. In comparison, however, the powertrain efficiencies are significantly lower, which leads to lower power efficiency in hover. A technology improvement in the sense of fuel cell-specific power brings a reduction in MTOM and thus an increase in energy efficiency. An improvement in terms of power efficiency in hover could not be observed. Here, however, the hybrid architectures are more advantageous than the fuel cell architecture due to their better powertrain efficiency in hover.

\section{VI.Conclusion and Outlook}

The aim of the study was to analyze and to examine the results and findings in the conceptual onboard systems design of UAM vehicles and to get deeper insights. Suitable and feasible concepts for electric powertrain architectures should be identified and used in the development of an air taxi system concept for the HorizonUAM project. 
For this purpose, a conceptual design methodology was developed, which enables the examination of full-electric, turbo-electric and hybrid-electric powertrain systems in the context of the multirotor design. This methodology is based on relatively simple models and assumptions. The models used are associated with uncertainties. The results should, in view of specific values, therefore be used with a certain amount of caution. Nevertheless, quantitative results seem to agree well with usual values in terms of the order of magnitude (e.g. masses, power). However, since the uncertainties are also the same for all models used, the results are also subject to the same uncertainties. That is why the qualitative differences in the results of the various powertrain architectures are particularly credible.

The methodology was used to investigate the impact of different electric powertrain architectures on the multirotor design. Furthermore, different evaluation parameters, parameter sweeps and technology exploration of batteries and fuel cell systems were applied to analyze and evaluate their impact on the UAM vehicle design. The results show that almost all configurations are feasible for different powertrain architectures, design ranges, and technology levels. The mission requirements for the intra-city use case (design range $50 \mathrm{~km}$ and payload $360 \mathrm{~kg}$ ) were met and the MTOM was clearly under the allowable mass. Only the configurations with full-electric architectures exceeded the allowable MTOM for design ranges greater than $100 \mathrm{~km}$.

The analysis showed that the main design drivers were the overall powertrain efficiency $\eta$ and the mass of the energy sources (battery and fuel cell). Powertrain architectures with high efficiency (e.g. full-electric, hybrid-electric with high $\Phi$ ) also show a higher power efficiency in hover compared to architectures with lower efficiency (e.g. fuel cell-based or hybrid-electric with low $\Phi$ ). The mass of the energy sources has a direct impact on the MTOM and the payload ratio, if the same payload is assumed. Furthermore, a higher MTOM leads to a lower energy efficiency of the configuration. It could be also shown that technological improvements such as increasing the battery specific energy and the fuel cell specific power could clearly reduce MTOM and thus increase the energy efficiency. With today's technology and with respect to MTOM and energy efficiency the analyses demonstrated that full-electric and hybridelectric architectures are advantageous for shorter ranges $(<50 \mathrm{~km})$, while architectures with fuel cell systems are more advantageous for longer ranges $(>50 \mathrm{~km})$.

The selection of the powertrain architecture depends on the sensitivity to various design and technology parameters. Architectures that lead to a low MTOM should be selected for an energy-efficient configuration. Architectures that have a high efficiency $\eta$ should be selected for a power-efficient configuration. However, it is exactly these architectures that lead to heavy and therefore energy-inefficient configurations. For that reason, no architecture was found that fulfills both parameter demands in an optimal manner.

To remedy this, the mission requirements must either clearly speak in favor of a light, energy-efficient configuration or a heavy, power-efficient configuration. Alternatively, a suitable power management could increase the performance and energy efficiency in different flight phases and thus, the overall efficiency of the aircraft. The disadvantages of a high mass of a pure full-electric solution based on batteries, for instance, could be at least partially reduced. This can be achieved through the use of hybrid-electric solutions (e.g. parallel hybrid-electric, fuel cell and battery). However, these architectures increase the system complexity, costs and maintenance effort, among other things.

The design methodology described above will be further developed in future works. The application of this methodology will be mainly in derivation of system design and component requirements, e.g. torque and speeds for the electric motors. Furthermore, the methodology has already been integrated into a higher-level simulation model in order to show the influence of the onboard systems on the design and operation of an UAM system [20]. For further research, a full-electric architecture based on batteries as well as a hybrid powertrain architecture with fuel cells and batteries will be investigated. Research will be carried out with regard to the safety-critical design as well as thermal management of these powertrain systems, safety and reliability analyzes, certification aspects and the overall modeling of the onboard systems.

\section{References}

[1] Schuchardt, B. et.al. "Urban Air Mobility Research at the DLR German Aerospace Center-Getting the HorizonUAM Project Started”. In AIAA Aviation 2021 Forum (p. 3197), Virtual, 2021. DOI: https://arc.aiaa.org/doi/10.2514/6.2021-3197

[2] Bertram, O., "Stand der Technik und Forschung zu Bordsystemen von Lufttaxis (in German, English title: State of the Art and Research on Onboard Systems of Air Taxis)". DLR internal report, DLR-IB-FT-BS-2021-93. 2021.

[3] Vertical Flight Society. "Electric VTOL Wheel of Fortune". https://evtol.news/news/commentary-electric-vtol-wheel-offortune [retrieved 26 Nov 2021].

[4] AirMed \& Rescue. "VTOL Volocopter demonstrated at Paris Air Forum". https://www.airmedandrescue.com/latest/news/ vtol-volocopter-demonstrated-paris-air-forum [retrieved 26 Nov 2021]

[5] Johnson, W., Silva, C., Solis, E., "Concept Vehicles for VTOL Air Taxi Operations". AHS Specialists' Conference on Aeromechanics Design for Transformative Vertical Flight, San Francisco, California, USA, 2018. 
[6] Goyal, R., Reiche, C., Fernando, C., Jacquie Serrao, J. D., Kimmel, S., Cohen, A., Shaheen, S., "UAM Market Study Technical Out Brief', 2018. No. HQ-E-DAA-TN65181. https://ntrs.nasa.gov/api/citations/20190001472/downloads/ 20190001472.pdf [retrieved 26 Nov 2021]

[7] Lutsey, N., Nicholas, M. "Update on Electric Vehicle Costs in the United States through 2030." The International Council on Clean Transportation 2, 2019. DOI: http://dx.doi.org/10.13140/RG.2.2.25390.56646

[8] Brelje, B. J., Martins, J. R., "Electric, Hybrid, and Turboelectric Fixed-wing Aircraft: A Review of Concepts, Models, and Design Approaches". Progress in Aerospace Sciences. 2019, vol 104, p. 1-19. DOI: https://doi.org/10.1016 li.paerosci.2018.06.004

[9] De Vries, R., Brown, M., Vos, R., "Preliminary Sizing Method for Hybrid-electric Distributed-propulsion Aircraft". Journal of Aircraft, 2019, Vol.56, Issue 6, pp. 2172-2188. DOI: https://arc.aiaa.org/doi/pdf/10.2514/1.C035388

[10] Kurzweil, P., "Brennstoffzellentechnik - Grundlagen, Komponenten, Systeme, Anwendungen (in German, English title: Fuel Cell Technology - Basics, Components, Systems, Applications”, Springer-Verlag, Fachmedien Wiesbaden, 2013. ISBN: 978-3-658-00085-1.

[11] EASA. "Special Condition for VTOL Aircraft". 2019.

[12] EASA. "Certification Specifications for Normal-Category Aeroplanes (CS-23 Amendment 5) and Acceptable Means of Compliance and Guidance Material to the Certification Specifications for Normal-Category Aeroplanes (AMC \& GM to CS23)". 2020.

[13] EASA. "Certification Specifications, Acceptable Means of Compliance and Guidance Material for Small Rotorcraft (CS27)". 2021.

[14] EASA. "Proposed Means of Compliance with the Special Condition VTOL". 2020.

[15] Bertram, O., Jäger, F., Voth, V., Rosenberg, J., "Impact of Different Powertrain Architectures on UAM Vehicle Concepts". Deutscher Luft- und Raumfahrtkongress, Bremen, Germany and online, 2021.

[16] Leishman, G. J., "Principles of Helicopter Aerodynamics". Cambridge University Press, New York, 2006. https://books.google.com.au/books?id=nMV-TkaX-9cC\&hl=de

[17] Barra, F., Scanavino, M., Guglieri, G., "A Methodology for Multirotor Aircraft Power Budget Analysis". Aircraft Engineering and Aerospace Technology, Vol. 92, Issue 6, 2020. DOI: https://doi.org/10.1108/AEAT-09-2019-0183

[18] Vegh, J. M., Botero, E., Clark, M., Smart, J., Alonso, J. J., "Current Capabilities and Challenges of NDARC and SUAVE for eVTOL Aircraft Design and Analysis". In: 2019 AIAA/IEEE Electric Aircraft Technologies Symposium (EATS), Indianapolis, Indiana, USA. IEEE, 2019. S. 1-19. DOI: https://doi.org/10.2514/6.2019-4505

[19] Kadhiresan, A. R., Duffy, M. J., "Conceptual Design and Mission Analysis for eVTOL Urban Air Mobility Flight Vehicle Configurations". In: AIAA Aviation 2019 Forum, Dallas, Texas, USA, 2019. S. 2873. DOI: https://doi.org/10.2514/6.2019$\underline{2873}$

[20] Prakasha, P. S., Ratei, P., Naeem, N., Nagel, B., Bertram, O., "System of Systems Simulation driven Urban Air Mobility Vehicle Design and Fleet Assessment”. AIAA Aviation Forum, Virtual, 2021. DOI: https://doi.org/10.2514/6.2021-3200 